UNIVERSIDADE DE SÃo PaUlo

FACLLDADE DE FILOSOFIA, CIÊNCIAS E LETRAS

DEPARTAMENTO DE QUímica

\title{
SÔBRE A NATUREZA DOS ÁCIDOS COLEICOS
}

\author{
por \\ Paschoal Senise
}

Tese de doutoramento dirigida pelo

Prof. Dr. HEINRICH RHEINBOLDT

1942 
O presente trabalho foi elaborado durante o biênio 1939-1940. 
Deixo aqui consignados os meus mais profundos agradecimentos ao meu insigne mestre, o Prof. Dr. HEINRICH RHEINBOLDT, pelos preciosos conselhos com que sabiamente me orientou e pelo incansavel e estimulante interesse que dispensou à execução deste trabalho. 


\section{ÍN DICE}

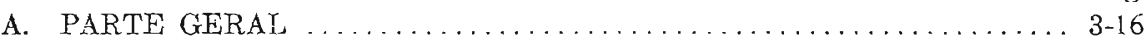

I. Sistemas binários de ácidos pararino-carboxílico-coleicos (Fig. III). . . . . 11

II. Sistemas binários do ácido esteárico-coleico com ácidos coleicos de carbhidretos

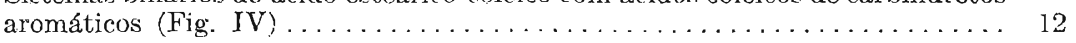

III. Sistemas binários de ácidos coleicos de (arbhidretos aromáticos (Fig. V.) 13

IV. Sistemas binários do ácido naftalena-apocólico com ácidos parafino-carboxílico-coleicos (Fig. VI) ................................

V. Sistema binário do ácido desoxicólico com ácido apocólico (Fig. VII.)..... 15

B. PARTE EXPERIMENTAL . . . . . . . . . . . . . . . . . . . . . 16-37

I. Sistemas binários de ácidos coleicos . . . . . . . . . . . . . 20-31

1. Ācido esteárico-coleico e ácido palmítico-coleico ................ 20

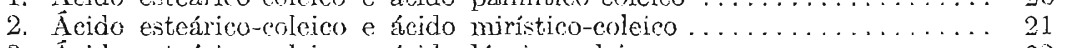

3. Äcido estéŕrico-coleico e ácido láurico-coleico $\ldots \ldots \ldots \ldots \ldots \ldots \ldots 22$

4. Ácido araquídico-coleico e ácido láurico-coleico .................. 22

5. Ácido esteárico-coleico e ácido naftalena-coleico ................ 23

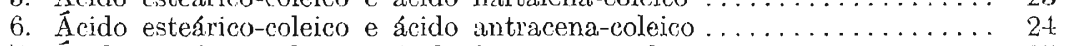

7. Ácido esteárico-coleico e ácido fenantrena-coleico .............. 25

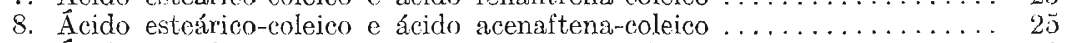

9. Ácido naft́alena-coleico e ácido antracena-coleico $\ldots \ldots \ldots \ldots \ldots \ldots \ldots 26$

10. Ácido naftalena-coleics e ácido fenantrena-coleico .............. 27

11. Ácido naftalena-coleien e ácido acenaftena-coleico $\ldots \ldots \ldots \ldots \ldots \ldots$. 28

12. Ácido antracena-coleico e ácido fenantrena-coleico $\ldots \ldots \ldots \ldots \ldots \ldots . \ldots \ldots 28$

13. Ácido antracena-coleico e ácido acenaftena-coleico . . . . . . . . . . . . 29

14. Ácido fenantrena-coleico e ácido acenaftena-coleico ............. 30

15. Ácido naftalena apocólico e ácido esté́rico-coleico $\ldots \ldots \ldots \ldots \ldots \ldots . . \ldots$

16. Ácido naftalena-apocólico e ácido mirístico-coleico $\ldots \ldots \ldots \ldots \ldots \ldots \ldots . . . \ldots \ldots$

II. Sistemas binários de moléculas simples. $32-37$

1. Ácido desoxicólico e ácido apocólico $\ldots \ldots \ldots \ldots \ldots \ldots \ldots \ldots \ldots \ldots \ldots \ldots \ldots$

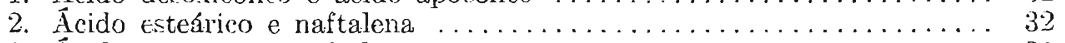

3. Fido mirístic e naftalena . . . . . . . . . . . . . . . . . . . . . . 33

4. Acido esté́rico e autrateni $\ldots \ldots \ldots \ldots \ldots \ldots \ldots \ldots \ldots \ldots \ldots \ldots \ldots, 34$

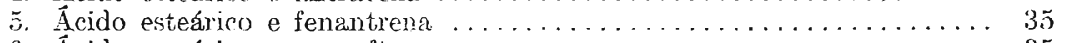

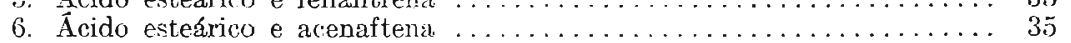

7. Naftalena e acenaftena ........................... 36

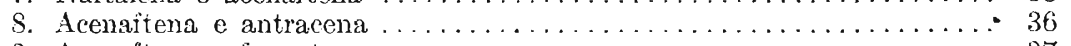

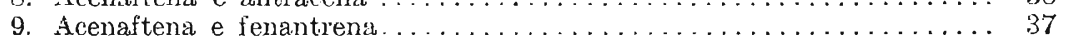


Em 1848 A STRECKER ${ }^{1}$ ) encontrou na bilis bovina os sais sódicos de dois ácidos caraterísticos, hoje conhecidos pelo nome de ácidos glico - e taurocólico, e provou que ambos, quando aquecidos com ácidos, fornecem, ao lado de glicocola (glicina) ou taurina, o mesmo produto de desdobramento: o ácido colálico, isto é, o atual ácido cólico, ao qual já então atribuiu a fórmula de constituição exata, $\mathrm{C}_{24} \mathrm{H}_{40} \mathrm{O}_{5}$. Estas experiências esclareceram numerosas observações anteriores.

Trinta e sete anos mais tarde, em 1885, P. LATschinof ${ }^{2}$ ) encontrou no mesmo material um segundo ácido, de P. F. 185-190², com menos oxigênio e que denominou: ácido coleico. - Pouco depois, F. Mrlius ${ }^{3}$ ) descobria na bilis bovina putrefata, ao lado dos outros dois, um terceiro ácido, de P. F. 160-170 , cuja fórmula se distinguia da estabelecida por STREckER para o ácido cólico, por possuir um átomo de oxigênio a menos, $\mathrm{C}_{24} \mathrm{H}_{40} \mathrm{O}_{4}$, e ao qual deu por isso o nome de ácido desoxicólico. - Provou-se mais tarde ser êste ácido um componente normal da bilis.

Latschinoff, ao contrário de Mylios, supôs que os ácidos coleico e desoxicólico fossem idênticos, mas outros pesquisadores, mais tarde, julgaram tratar-se de dois indivíduos definidos da mesma composição, passando a considera-los como isômeros. O fato ficou sem maiores esclarecimentos por muito tempo, a ponto de se encontrar na literatura, durante três décadas, usados indistintamente, os nomes "ácido coleico" e "ácido desoxicólico".

Coube a Wieland e Sorge elucidar a questão. H. Wieland e H. SorGE ${ }^{4}$ ), em 1916, ao submeterem o ácido coleico à destilação no alto vácuo, notaram nas primeiras frações do destilado a presença de um ácido graxo sólido. Levados então por essa observação inesperada, descobriram que do ácido coleico se pode obter facilmente o ácido desoxicólico, por caminhos diversos, mas sempre com separação de uma pequena quantidade de um ácido graxo superior. Esste ácido possue a composição analítica do ácido margárico mas na verdade é, como foi provado, uma mistura dos ácidos esteárico e palmítico e às vezes tambem oleico. Wreland e Sorge constataram tambem que pelo caminho inverso, isto é, pela simples cristalização conjunta de ácido graxo e ácido desoxicólico em alcool, pode-se facilmente sintetizar o ácido coleico. Concluiram então tratar-se, no caso do ácido coleico, de um composto de adição molecular e provaram que esta adição se dá na proporção de uma molécula de ácido graxo para oito de ácido desoxicólico. - O ácido graxo constitue, pois, uma pequenissima parte (ca.8\%)

1) A. Strecker. Jber. Chem. 1848, 896

2) P. Latschrvoff. B. 18, 3039 (1885); ; Jber. Chem. 1885. IY. 1838.

F. Mrurus. B. 19,374 (1886) ; Jber. Chem. 1886. II. 1848.

4) H. Wigland e H. Sorge. Ztsohr. physiol. Chem 97,1 (1916)

C. 1917. I. 60.; Chem. Abstr. 11.257. 
da enorme molécula do ácido coleico (P. M. 3420), e por isso não pôde ser descoberto pela análise elementar. Compreende-se assim porque os ácidos desoxicólico e coleico foram, durante algum tempo, tomados como isômeros.

Os mesmos autores constataram que o ácido desoxicólico pode unir-se tambem a outros ácidos parafino-carboxílicos e a outras moléculas orgânicas, p. ex. a substâncias aromáticas, formando compostos moleculares estáveis do tipo do ácido coleico. - Prepararam e analisaram os compostos reunidos na tabela 1.

$$
\begin{aligned}
& \text { Ácido esteárico + ácido desoxicólico - - - 1:8 - } \\
& \text { Ácido palmitico † ácido desoxicólico - - 1:8- } \\
& \text { Ấcido oleico + ácido desoxicólico - 1:8- } \\
& \text { Ácido caprilico + ácido desoxicólico.-1:5- } \\
& \text { Ácido butirico }+ \text { ácido desoxicólico. - - 1:4 } \\
& \text { Ācido própiônico + ácido desoxicólico. - - 1:3- } \\
& \text { Ácido acético }+ \text { ácido desoxicólico.-1:1- } \\
& \text { Xilena }+ \text { ácido desoxicólico.-1:2- } \\
& \text { Nâ̂talena } \quad+\frac{1}{+} \text { ácido desoxicólico - } 1: 2
\end{aligned}
$$

Tab. 1.

Qualitativamente tambem verificaram que pode o ácido desoxicólico unir-se a alcool etílico, éter, benzena, ácido benzóico, benzaldeído, cânfora, fenol, carvona, salol, e colesterol. - Hoje pode-se dizer que o ácido desoxicólico forma compostos moleculares com representantes de quasi todas as classes de compostos orgânicos, e a todos esses compostos dá-se, por proposta de Wiezand, a designação geral de ácidos coleicos.

Existe pois uma distinção clara entre:

1. ${ }^{\circ}$ Acidos biliares conjugados, encontrados na bilis em forma copulada, com glicocola ou taurina, e que pela hidrólise fornecem um assim chamado "ácido biliar específico".

Ex. :

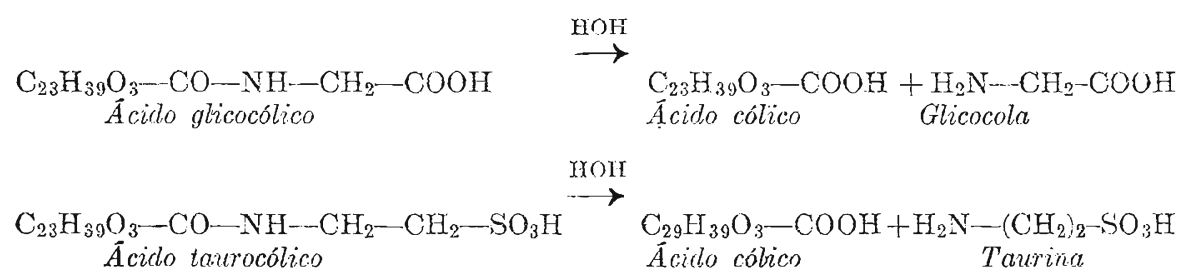

A constituição dos ácidos glico--- e taurocólico foi provada pela síntese dos compostos $)^{5}$.

5) S. Bondi e E. Mueller. Ztschr. physiol. Chem. 47,499(1906); C. 1906. I. 1733.

F. Cortese e L. Bauman. Am. Chem. Soc. 57,1393(1935); C.1995.II. 2676.; Chem Abstr. 29,624t. 
2. ${ }^{\circ}$ Ácidos biliares especificos, isto é, ácidos biliares resultantes da hidrólise dos primeiros, como, por exemplo, os ácidos cólico, desoxicólico e outros que adiante veremos.

$3{ }^{0}$ Ácidos coleicos, isto é, compostos de adição molecular do ácido desoxicólico. Entre êstes distingue-se corn o nome "ácido coleico natural", o composto molecular do ácido desoxicólico com ácidos graxos superiores (ácidos esteárico, palmítico, oleico) existente na bilis animal. - A molécula. orgânica ligada ao ácido desoxicólico é tambem designada por "componente acólico" (SoвотkA).

Os ácidos coleicos diferem do ácido desoxicólico não só pela facilidade com que cristalizam, mas tambem em todas as propriedades importantes, como o mostra a tabela 2 para um dos ácidos coleicos.

Forma cristalina

Solubilid. en alcool a frio

Solubilid. em alcool at quente

Soluh. em ace acéticos a frio P.in

\begin{tabular}{|c|c|}
\hline $\begin{array}{c}\text { Acido } \\
\text { palmiticos- } \\
\text { coleico }\end{array}$ & $\begin{array}{c}\text { Acido } \\
\text { desoxicólic's }\end{array}$ \\
\hline & \\
\hline Rombicad & Tetragonal \\
$1: 18$ & $1: 4$ \\
$1: 5$ & $1: 2$ \\
muito & mouco \\
$+19^{\circ}, 28^{\prime}$ & $+57^{\circ}, 02^{\prime}$ \\
$184-185^{\circ}$ & $172^{\circ}$ \\
\hline
\end{tabular}

Tab. 2.

WIeland e Sorge constataram que os sais alcalinos de ácidos coleicos com componentes acólicos insolúveis, se dissolrem perteitamente em água. Na opinião dêśses autores a formação de ácidos coleicos no intestino estaria intimamente relacionada com a importante função ficiológica dos ácidos biliares de tornar solúveis numerosas substâncias insolúveis em água, solıretudo os ácidos graxos superiores. A solubilidade dos sais sódicos é mesmo aproveitada para ministrar ao organismo em forma hidro-solúvel, por intermédio dos seuś ácidos coleicos, certas substâncias insolúveis ou pouco solúveis como, por exemplo, cânfora ${ }^{8}$ ) - Wikland deu a êste fenômeno fisiológico da solubilização de substâncias insolúveis pela formação de sais coleicos solúveis, a designação de "principio coleico".

E importante notar que a extraordinária faculdade de formar compostos moleculares do tipo dos ácidos coleicos não é possuida por nenhum dos demais ácidos biliares específicos ou compostos semelhantes conhecidos. Este fato foi rigorosamente provado por H. RHErnboumt ${ }^{7}$ ) para os ácidos cólico e hiodesoxicólico, como tambem para o colesterol, pelo exame dos

6) H. Rheivioudt. Zt.chr. physiol. Chem. 184,219(1929); C. 1980.1.1310.: Chem. Abstr. 24,376.

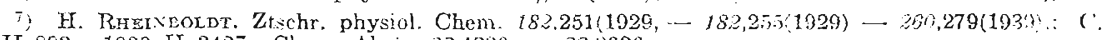
1929. II. 893 : 1939 II. 3427 . Chem. Abstr. 23,4226. - 39, 3636. 
diagramas de estado dos sistemas binários dêsses compostos com ácidos graxos.

Os ácidos biliares específicos naturais mais importantes são todos derivados hidroxilados do composto fundamental: ácido colânico.

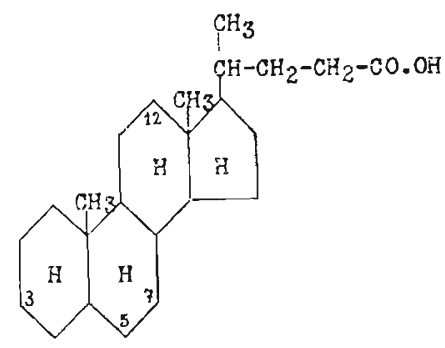

Ácido colânico

Acido desoxicólico, isto é, ac. 3,12-dioxicolânico.

Ácido hiodesoxicólico, ${ }^{8}$ ) isto é, ac. 3,6-dioxicolânico.

$\bar{A}$ cido ântropo- ${ }^{9}$ ) ou quenodesoxicólico ${ }^{10}$ ), isto é, ac. 3,7-dioxicolânico. Ácido cólico, isto é, ac. 3,7,12-trioxicolânico.

Ácido litocólico, ${ }^{11}$ ) isto é, ac. 3-oxicolânico.

Somente um ácido artificial, o ácido apocólico ou ácido 3,12-dioxicolênico-8,9, obtido por F. BoedeCKER ${ }^{12}$ ) pela deshidratação parcial do ácido cólico, forma compostos moleculares do tipo dos ácidos coleicos. ${ }^{12}{ }^{13}$ ). Já o seu isômero, o ácido 3,12-dioxicolênico-7,8 que dêle difere pois só pela posição da dupla ligação na molécula, não possue mais a mesma propriedade $\left.{ }^{14}\right)$.

A faculdade de formar ácidos coleicos é, portanto, extraordinariamente específica e ainda não esclarecida quanto à sua causa.

8) "Hyodesoxychclsaeure" - isolado da bilis suina por A. WINDAus e A. Borne, Ann. 488,279(1923); C. 1924. I. 1043; Chem. Abstr. 18,81.

9) "Anthropo-desoxycholsaeure" - encontrado na bilis humana por H. WreLAND, Ztschr. physiol. Chem. 140,186(1924); C.1924.II. 276.5.; Chem Abstr. 19,641.

10) "Cheno-desoxycholsaeure" — isolado da bilis de ganso por A. Windaus, A. Bohne, E. SchwarzEOPF e A. van Schoor, Ztschr. physiol. Chem. 140,177(1924); C. 1924. II. 2764.; Chem. Abstr. 19,640.

11) "Lithocholsaeure" - descoberto em cálculos biliares por H. FIscHer, Ztschr. physiol. Chem. 73,234(1911); C. 1911. In. 1238. Provado como componente normal da bilis por H. WIEL.1ND e P. WEYLAND, Ztsrihr. physiol. Chem. 110,123(1920) ; C. 1920. IrI.591.; Chem. Abstr. 15,1730.

12) F. BOEDECKER. B. $58,1852(1920)$; C. 1920. III.929.; Chem. Abstr. 15,858.

13) H. Rheinвoldt. Ann. 451,256(1927); C.1927. I. 1569.; Chem. Abstr. 21.1127. - Ztschr. physiol. Chem. 180,180(1929); C.1929. I. 2060; Chem. Abstr. 23,1906. - Ztschr. physiol. Chem, 184,219 (1929); C.1930.I.1310.; Chem. Abstr. 24,376. - Journ. prakt. Chem. [2] 153,313(1939); C. $1939 . I 1$. 2930.; Chem. Abstr. 84,113.

14) F. Bosdecker. B. 54,2489(1921); C. 19:2. I. 46.; Chem. Abstr. 16,1 217. 
Os ácidos coleicos constituem a classe mais estranha dos compostos moleculares orgânicos, não só pelo já mencionado extraordinário poder de adição dos ácidos desoxicólico e apocólico, mas tambem e principalmente pela sua original composição. Com efeito, uma estatística publicada por H. RheinboldDT ${ }^{15}$ ) em 1926, mostra que os compostos moleculares orgânicos possuem, na maioria dos casos, composições muito simples: $1: 1$ ou 1:2. As proporções de composição 1:4 e 1:6, encontradas nos ácidos coleicos, são extremamente raras, e a de 1: 8 é completamente desconhecida. A tabela 3, extraida dessa estatística, mostra a composição de 320 compostos, pertencentes às mais diferentes classes e todos examinados em relação ao seu diagrama de estado.

\begin{tabular}{|cccccc|}
\hline $1: 1$ & $1: 2$ & $2: 3$ & $1: 3$ & $1: 4$ & $1: 6$ \\
205 & 844 & 13 & 9 & $\gamma$ & $\mathcal{Z}$ \\
$64,1 \%$ & $26,2 \%$ & $4,1 \%$ & $2,8 \%$ & $2,2 \%$ & $0,6 \%$ \\
\hline
\end{tabular}

Tab. 3.

No que diz respeito à constituição dos ácidos coleicos, Wrezand e Sorke ${ }^{4}$ já haviam constatado que o número das moléculas de ácido desoxicólico unido a uma molécula de áciclo graxo, aumenta com pêso molecular crescente do último, e haviam concluido, do fato de não se poder obter ácido coleico do ácido fórmico, que as moléculas de ácido desoxicólico se ligam à do ácido graxo por intermédio dos grupos metilênicos e metílicos que esta possue. Não puderam porém estabelecer uma relação aritmética entre o número dêstes grupos e o das moléculas de ácido desoxicólico.

Afim de melhor esclarecer a constituição dessa estranha classe de compostos moleculares, H. Rheinbold ${ }^{16}$ ) executou, a partir de 1923, uma longa série de pesquisas. - Após provar pela primeira vez, mediante o exame dos diagramas de estado, que os ácidos coleicos e os compostos análogos do ácido apocólico são efetivamente compostos químicos definidos ${ }^{17}$ ), Rheinboldt iniciou o estudo sistemático dos ácidos coleicos da série homóloga dos áciclos parafino-carboxílicos. Após sintetizar e examinar a composição de 18 compostos dessa série, o autor pôde concluir que se apresentam apenas determinadas e distintas proporşões de composição em que ha uma certa relação com o comprimento da cadeia do ácido graxo, mas que estas proporções não aumentam em progressão aritmética com o crescimento da cadeia carbônica.

15) H. Runingoldt. Ztschr. angew. Chem. 39,767(1926); C.1926. Ir. 2657. Chem. Abstr. 20,3693.

16) H. Rhninsoldt. Ztschr. angew. Chem. 87,834(1924). - Ann. 451,256(1927); C. 192\%. I. 1569.; Cbem. Abstr. 21,1127.

17) H. Rarninoldt. An3. 451,256-273(1927). - Ztschr. physiol. Chem. 180,180(1929); C. 1929.I. 260.; Chem. Abstr. 23,1906. 
Rheinbold encontrou para os ácidos coleicos do
Ácido butírico
até o ácido caprílico
Acido pelargônico
até o ácido mirístico
a proporção $\left.1: 4 .{ }^{18}\right)$
a proporção $1: 6$.
pentadecanoico até o ácido montanóico a proporção 1:8.

A fig. I mostra os três períodos caraterísticos para os ácidos coleicos da série homóloga dos ácidos parafino-carboxílicos.

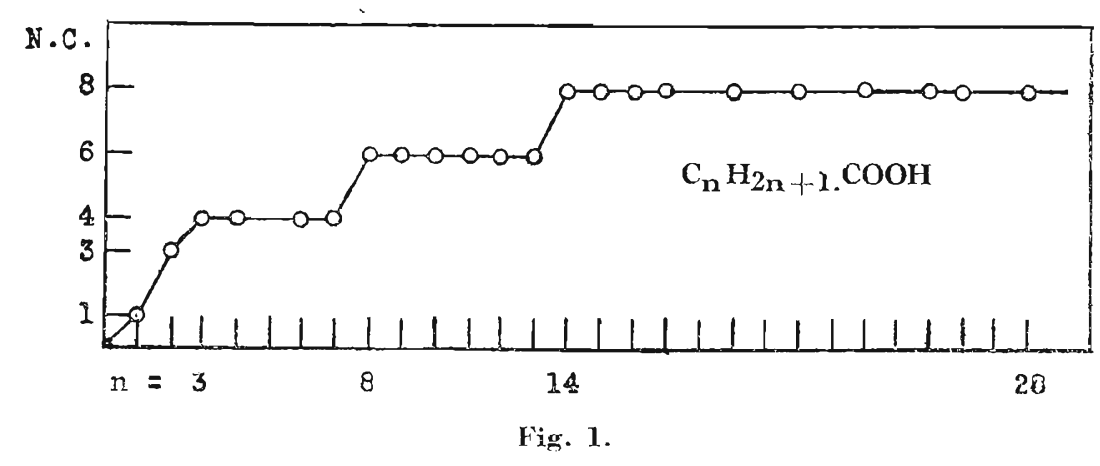

Diagrama da composição dos ácidos parafino-carboxílico-coleicos.

Oito exemplos de ácidos olefino-carboxílicos encadeiam-se no mesmo sistema formando ácidos coleicos correspondentes aos dos ácidos saturados, c de maior estabilidade.

Entre as proporções encontradas para a composição dos ácidos colcicos as de 1:4,1:6,1:8, completamente descomunais nos compostos moleculares orgânicos, eram já conhecidas, descle AlFred WERner, como particularmente caraterísticas para complcxos de coordenação inorgânicos. Estes complexos nunca apresentam as proporções 1:5 e 1:7 quando todos os ligantes coordenados ao átomo central são iguais. - Baseado pois nesses resultados experimentais, Rheinboldt lançou a hipótese segundo a qual os ácidos coleicos, em analogia com os complexos inorgânicos, seriam constituidos de acordo com o princípio da coordenação, de modo que, ao redor de uma molécula orgânica figurando como centro de coordenação do complexo, se distribuiriam em conhecida orientação espacial, as moléculas de ácido desoxicólico, chegando-se no máximo até o número de coordenação cúbica 8. Cabe pois, aos diferentes componentes acólicos dos ácidos coleicos um número de coordenação definido.

Como os complexos livres dos ácidos coleicos não são conhecidos, esta hipótese só se refere aos compostos cristalizados. RHeinbold admitiu por isso que nos ácidos coleicos, assim como sucede nos complexos inorgâtnicos perfeitos, cada um dos nós do retículo cristalino estaria ocupado por um complexo inteiro. O Autor designou os ácidos coleicos por "compostos

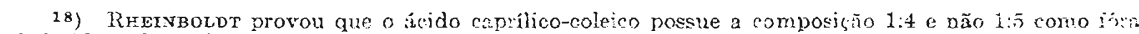
estabelecido, a base de análises pouco satiefatórias, por WiELAND e Sorge. 
moleculares de espécie superior" em contraposição aos "compostos moleculares de primeira espécie" em que, segundo a opinião geral dessa época, os nós dos retículos seriam centros de moléculas simples.

As mesmas proporções de composição dos mais diversos ácidos coleicos foram confirmadas por numerosos trabalhos posteriores, quer por RHErNBOLDT, quer por vários outros autores. Nunca porém foram constatadas as proporçoes 1:5 e 1:7, fato este que só pode dar maior Iorça à hipótese coordenativa, pois, tais composições não permitiriam uma distribuição espacial simétrica, a única admissivel em complexos de ligantes iguais.

Dentre os trabalhos posteriores mais importautes, salientamos os de Rheinbold ${ }^{19}{ }^{19}$ ) em 1929 e 1939, e o de Sobotka e Goldberg ${ }^{20}$ ) em 1932. No primeiro foram estudados 56 ácidos coleicos dos ésteres de ácidos parafino-carboxílicos, tendo-se registrado sempre as mesmas proporções de composição já mencionadas. Rheinboldt constatou que o número de coordenação não depende do número total dos átomos de carbono da molécula do éster, mas é determinado unicamente pelo comprimento da cadeia carbônica mais longa, pertença cla ao resto alcoolico ou ao ácido. O laurato de n-hexilo, $\mathrm{C}_{18} \mathrm{H}_{36} \mathrm{O}_{2}$, por exemplo, não possue, como seria de esperar, o número de coordenação 8, como o seu isômero, o ácido esteárico, $\mathrm{C}_{18} \mathrm{H}_{36} \mathrm{O}_{2}$, mas apenas o número de coordenação 6 .

Rheinbold demonstrou tambem, por meio de vários exemplos comparativos, que o grupo carboxílico, $-\mathrm{CO}_{2} \mathrm{H}$, nenhuma influência exerce no número de coordenação dos ácidos coleicos dos ácidos graxos, o mesmo sucedendo com o resto do ácido fórmico, $\mathrm{H} . \mathrm{CO}_{2}-$, nos ácidos coleicos dos ésteres fórmicos isômeros dos primeiros.

Para maior esclarecimento deste fenômeno importante apresentamos, na tabella 4, alguns dos exemplos examinados:

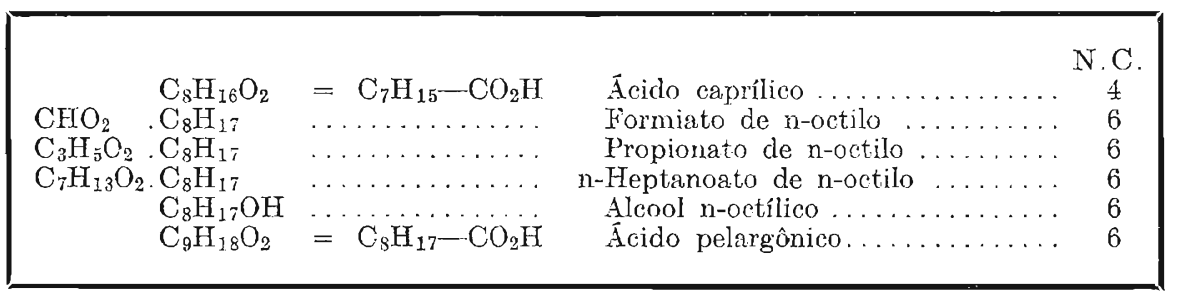

Tab. 4

O Autor concluiu desse fato que deveria ser possivel a formação de ácidos coleicos de carbhidretos alifáticos, o que conseguiu provar experimentalmente $\left.{ }^{19}\right)^{21}$ )

19) H. Rheinboldt e Colab. Ann. 473,249(1929); C. 1929.II. 1650.; Chem. Abstr. 29,4926 26,55711

20) H. Sовотқа e A. Goldberg. Biochem. Journ. 26,557(1932); C. 1932.II. 2826.; Chem. Abstr.

\footnotetext{
21) H. Reginbordr. Journ. prakt. Chem. [2]159,313(1939); C. 1999. II. 2930.; Chem. Abstr. $94,113$.
} 
O trabalho de H. Sobotka e A. Goldberg ${ }^{20}$ ) refere-se aos ácidos coleicos dos ácidos parafino-dicarboxílicos. As proporções encontradas, com exceção do número de coordenação 8 que nestes casos não foi registrado, são as mesmas dos trabalhos precedentes, como se vê no gráfico da fig. II.

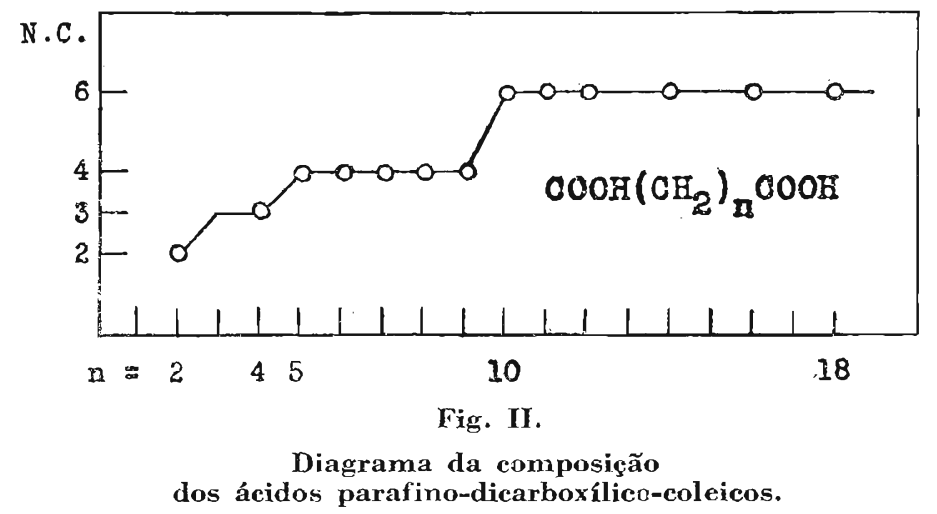

Devido pois, à grande concordância das proporçốs de composição dos ácidos coleicos com os números típicos de coordenação a hipótese de Rheinbold da construção coordenativa desses cumpcstos mereceu os maiores aplausos e foi aceita integraimente, servindo até hoje como base de todas as discussões ness' classe de compostos moleculares orgânicos.

Pesquisas roentgenográficas executadas por $\mathrm{Y}$. Go e O. KRATKr22) em 1934 e ampliadas por O. Kratky e G. Giacomello ${ }^{23}$ ) em 1936, mostraram que alguns ácidos coleicos dos ácidos parafino-carboxílicos fornecem roentgenogramas praticamente concordantes, não obstante o número de coordenação diverso. Este fato, que indica uma estrutura cristalina semelhante, seria talvez, na opinião dos autores, contrária à hipótese da construção coordenativa desses compostos. Êsses resultados roentgenográficos são porém considerados duvidosos por outros autores.

Em vista disso, quis o Prof. Rheinnold submeter os ácidos coleicos a novo exame sistemático e sugeriu-nos, como tema de uma nova pesquisa, a tarefa de provar pela experiência as possibilidades de isomorfismo entre os diversos ácidos coleicos.

O trabalho consistiu essencialmente em formar sistemas binários de vários ácidos coleicos e determinar os respetivos diagramas de estado por meio da análise térmica. Adotámos este método de pesquisa afim de poder basear nossas conclusões, sobre a suposta isomorfia dos compostos em estudo, na possibilidade da formação de séries contínuas de cristais mistos. $29,191$.

22) Y. Go e O. Kratry. Ztschr. physik. Chem. (B) 26,439(1934); C. 1996. I. 2565.; Chem Abstr. $\$ 1,3358$.

O. Kratky e G. Giacombllo. Monasth. Chem 69,427(1936); C. 1987.1.3157.; Chem. Abstr . 
Os diagramas foram determinados segundo o método de H. RHeinBoLDT, "Auftau-Schmelzmethode", que descreveremos na parte experimental.

Em primeiro lugar dirigimos nossa atenção para os ácidos coleicos dos ácidos graxos superiores iniciando o estudo com o sistema.

1) Ácido esteárico-coleico (1:8) + ácido palmítico-coleico (1:8).

Verificámos a formação de uma série contínua de cristais mistos e obtivemos um diagrama do tipo I da classificação de H. W. Roozeвoom ${ }^{24}$ ). Este resultado não constitue surpresa, pois, tratando-se de complexos de número de coordenação idêntico, é perfeitamente compatível com a hipótese de constituição já mencionada. Examinámos porém outros sistemas binários dessa série usando, como componentes, ácidos coleicos de partes acólicas de número de coordenação diferente:
2) Ácido esteárico-coleico
$(1: 8)+$ ácido mirístico-coleico (1:6)
3) Arids esteárico-coleico
$(1: 8)+$ ácido láurico-coleico
4) Ácido araquidico-coleico
(1:8) + ácido láurico-coleico
$(1: 6)$.

Obtivemos em todos estes casos diagramas de estado do mesmo tipo I, e portanto sempre séries contínuas de cristais mistos.

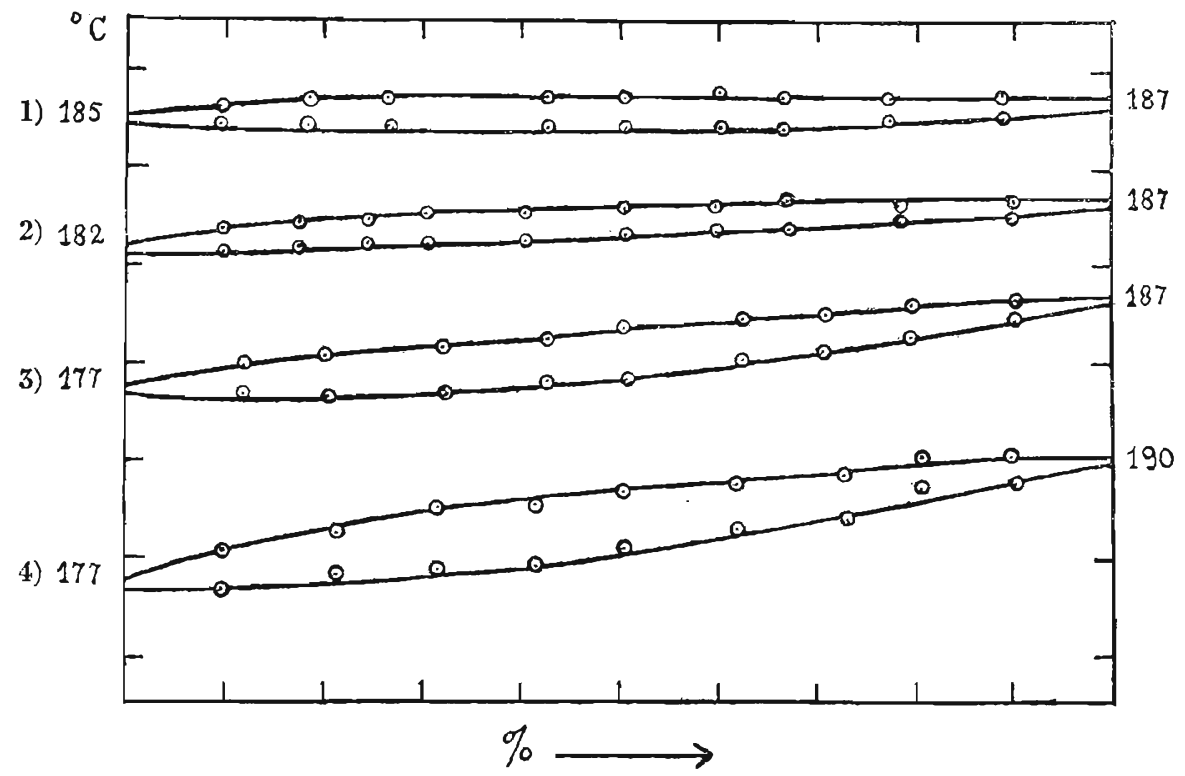

Fig. III.

Diagramas de estado de sistemas binários de ácidos parafino-carboxílico-coleicos.

24) H. W. Roozeroom. Ztschr. physik. Chem. 30,385 (1899); C. 1900. I.7,8. 
Desses diagramas de estado, reunidos na figura. III, conclue-se que os ácidos coleicos dos ácidos graxos superiores são isomorfos.

Esta isomorfia dos ácidos coleicos desses ácidos parafino-carboxílicos poderia talvez encontrar sua explicação numa possivel, mas ainda não provada, isomorfia dos proprios ácidos graxos que figuram, nos ácidos coleicos examinados, como componentes acólicos. Julgámos por isso necessário formar sistemas binários com ácidos coleicos de componentes acólicos de tipo completamente diferente, e estudámos sistemas binários do ácido esteárico-coleico com ácidos coleicos de carbhidretos aromáticos:

1) Ácido esteárico-coleico (1:8) + ácido naftalena-coleico (1:2)

2) Ácido esteárico-coleico (1:8) + ácido antracena-coleico (1:4)

3) Ácido esteárico-coleico (1:8) + ácido fenantrena-coleico (1:3)

4) Ácido esteárico-coleico (1:8) + ácido acenaftena-coleico (1:2).

Não obstante a grande diversidade dos componentes acólicos, obtivemos, em todos os casos, séries contínuas de cristais mistos com diagramas semelhantes ao tipo III, caraterizados pela forma convexa das curvas, que reunimos na figura IV.

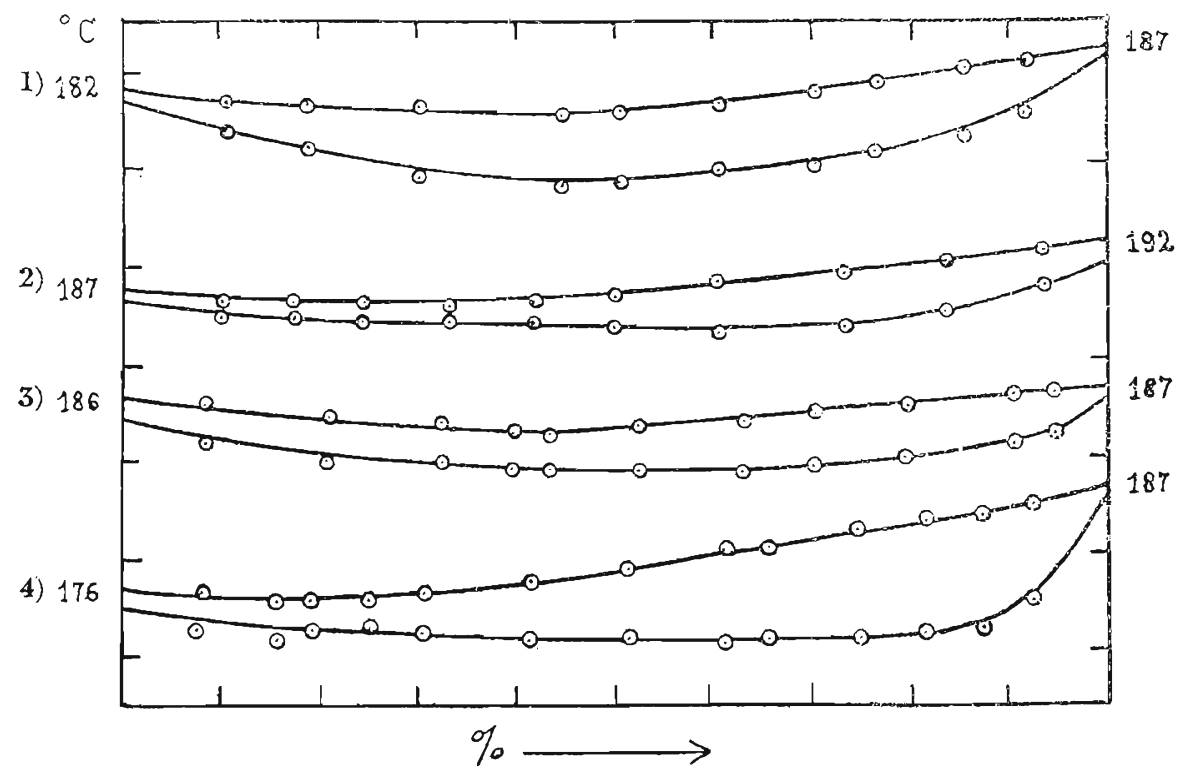

Fig. IV.

Diagramas de estado de sistemas binários do ácido esteárico coleico com ácidos coleicos de carbhidretos aromáticos.

Afim de comprovar que não existe isomorfismo entre os componentes acólicos desses ácidos coleicos, determinámos os diagramas de estado dos sistemas: 
Ácido esteárico + naftalena - P. eutético: $24 \%$ naft. $/ 55^{\circ} \mathrm{C}$

Ácido esteárico + antracena - " " $2 \%$ antr. $67^{\circ} \mathrm{C}$.

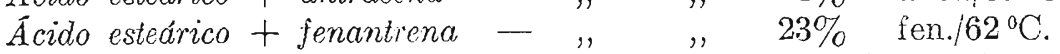

$\bar{A}$ cido estéárico + acenaftena - " , $, \quad 22,5 \%$ acen. $/ 60,5^{\circ} \mathrm{C}$.

Constatámos que estas substâncias não formam cristais mistos, mas conglomerados, mostrando todos os diagramas um simples eutético.

Num terceiro grupo de experiências examinámos os sistemas binários dos ácidos coleicos de carbhidretos aromáticos:

1) Ácido naftalena-coleico (1:2) + ácido antracena-coleico (1:4)

2) Ácido naftalena-coleico (1:2) + ácido fenantrena-coleico (1:3)

3) Ácido naftalena-coleico $(1: 2)+$ ácido acenaftena-coleico (1:2)

4) Ácido antracena-coleico (1:4) + ácido fenantrena-coleico (1:3)

5) Ácido antracena-coleico (1:4) + ácido acenaftena-coleico (1:2)

6) Ácido fenantrena-coleico(1:3) + ácido acenaftena-coleico (1:2)

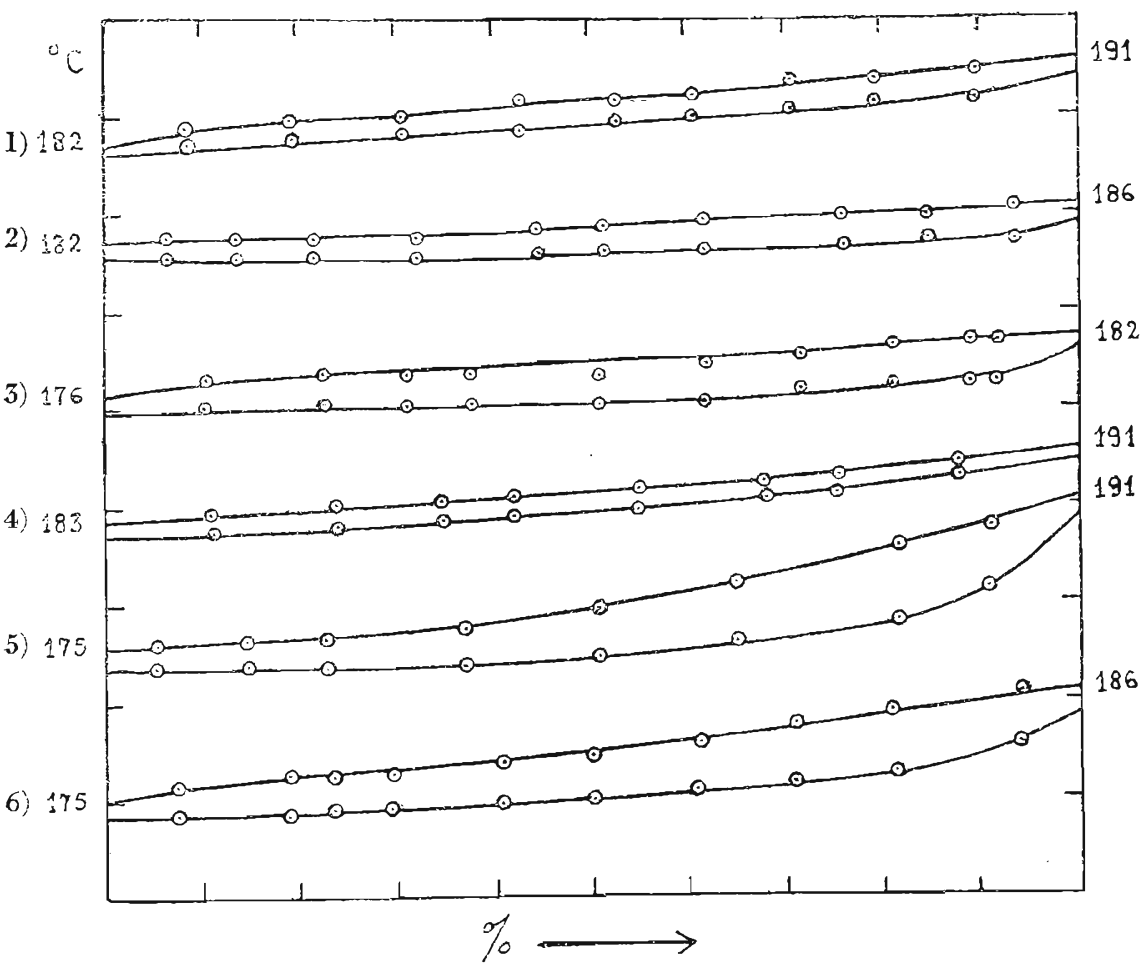

Fig. V.

Diagramas de estado de sistemas binários de ácidos coleicos de carbhidretos aromáticos. 
Os seis diagramas de estado obtidos, reunidos na figura $\mathrm{V}$, todos do tipo I, atestam a formação de séries ininterruptas de cristais mistos.

Os carbhidretos aromáticos contidos nesses ácidos coleicos, com exceção de um único caso já conhecido, antracena e fenantrena, ${ }^{25}$ ) que formam cristais mistos do tipo I, não são isomorfos entre si. - Foram por nós estudados os sistemas binários:

$$
\begin{aligned}
& \text { Naftalena + acenaftena - P. eutético: } 43 \% \text { acen. } / 52^{\circ} \mathrm{C} \text {. } \\
& \text { Antracena + acenaftena - }, \quad, \quad, \quad, 5 \% \text { antr. } / 89^{\circ} \mathrm{C} \text {. } \\
& \text { Fenantrena + acenaftena - }, \quad, \quad 54,5 \% \text { fen. } / 59^{\circ} \mathrm{C} .
\end{aligned}
$$

sendo já conhecidos os sistemas: Naftalena + antracena ${ }^{26}$ ) e naftalena + fenantren $a^{27}$. Em todos estes casos ha sempre formação de conglomerados sendo os diagramas caraterizados por um bem distinto ponto eutético e pela constância dos pontos de fusão da mistura eutética.

$\hat{\mathrm{E}}$ interessante notar que quando ambos os componentes do sistema binário são ácidos coleicos de ácidos graxos ou ambos de carbhidretos aromáticos, o diagrama resultante é sempre do tipo I, mas quando um dos componentes é um ácido coleico de um ácido graxo e o outro o de um carbhidreto aromático, o diagrama pertence sempre ao tipo III da classificação de Roozeboom.

Em vista do comportamento idêntico dos ácidos apocólico e desoxicólico na formação de compostos de adição molecular, determinámos os diagramas de estado tambem para os sistemas binários:

1) Ácido naftalena-apocólico (1:2) + ac. esteárico-desoxicólico (1:8)

2) Ácido naftalena-apocólico $(1: 2)+$ ac. mirístico-desoxicólico (1:6)

Verificámos, como no caso dos ácidos coleicos propriamente ditos, a formação de séries contínuas de cristais mistos do tipo III. (Fig. VI). Provámos ainda que naftalena e ácido mirístico não formam cristais mistor, mas conglomerados.

25) L. VignoN. BI. [3] 6,387(1891); C. 1891 ; II. 539.

F. Garelit. Gaz. It. 24.II.263(1894); C. 1894.II.771. 27,4471 .

G. Bradiey e J. K. Marsch. J. Chem. Soc. London 1983,650 ; C. 1938.II. 1182.; Chem. Abstr.

26) L. Vignon. 1. e. - A. Mrolati. tschr. physik. Chem. 9,653(1892) C. 1892. II. 347. - E. IR UDOLFY. id. $66,722(1909) ;$ C. 1909. II. 331.

27) L. Vrgnon. 1. c. - A. Mrolati. 1. c. - E. Redolfr. 1. c. 26,5487 .

M. Milone e P. Rossignorr. Gaz. It. 62,614(1932); C.1982.II.1275,2609.; Chem. Ab-tr. 


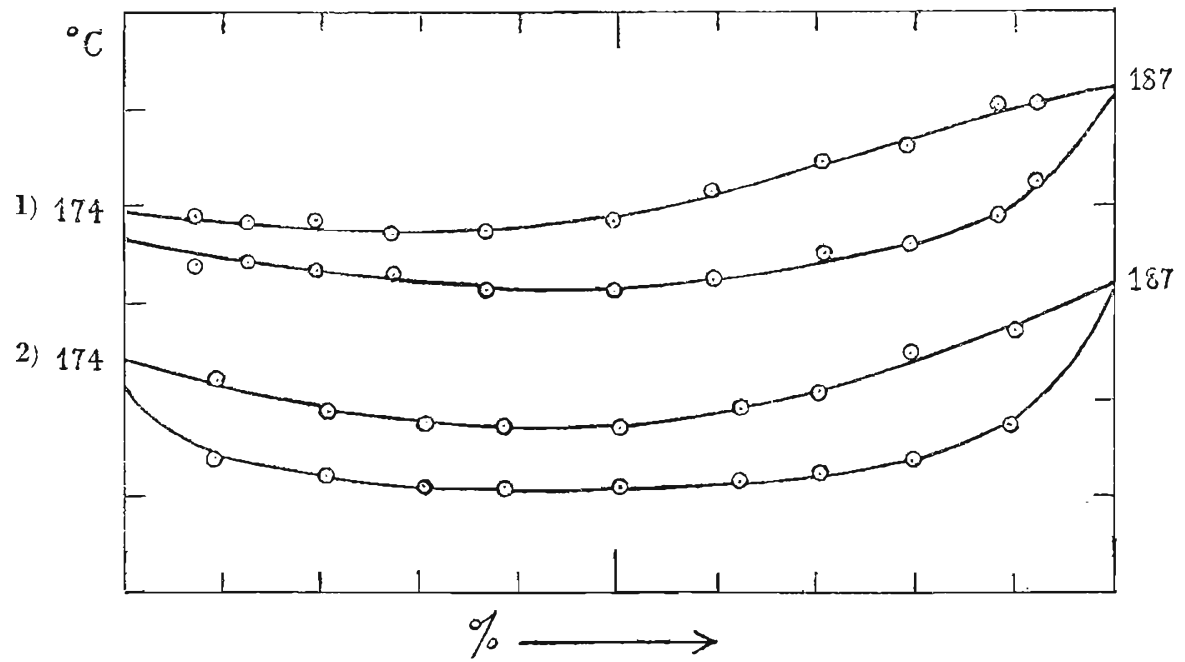

Fig. VI.

Diagramas de estado de sistemas binários do ácid o naftaIena-apocólico com ácidos parafino-carboxílico-coleicos.

Estudámos finalmente o comportamento recíproco dos ácidos apocólico e desoxicólico e constatámos que ambos formam entre si uma série ininterrupta de cristais mistos. (Fig. VII.).

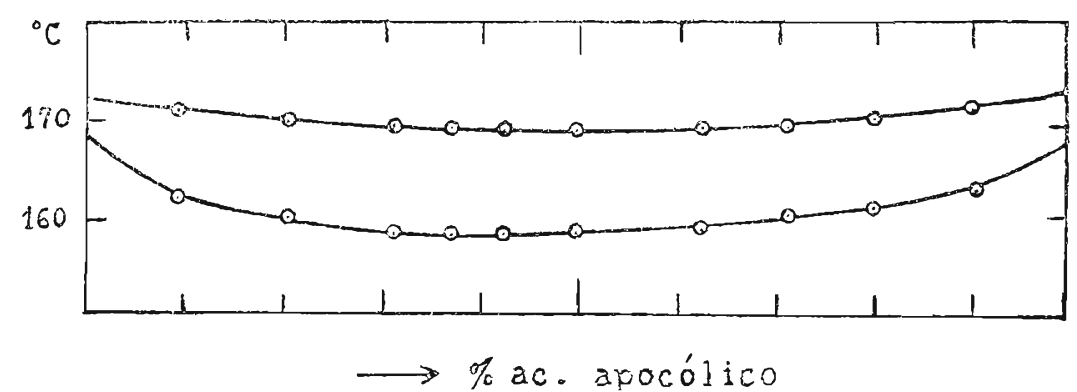

Fig. VII.

Diagrama de estado do sistema binário : ácido desøxicólico + ácido apocólico.

Ácido apocólico e ácido desoxicólico são, portanto, isomorfos, fato que explica perfeitamente o comportamento análogo de ambos os ácidos na formação de compostos de adição. 
Dos resultados apresentados póde-se concluir que todos os ácidos coleicos estudados são isomorfos. - Desta isomorfia dos ácidos coleicos resulta que, por mais diversos que sejam a natureza dos componentes acólicos e os "numeros de coordenação", os ácidos coleicos devem possuir sempre o mesmo ou um bem parecido retículo cristalino, retículo este que, como se sabe, não é idêntico ao do proprio ácido desoxicólico.

Este isomorfismo dos ácidos coleicos leva a crer que nos seus cristais os diferentes componentes acólicos possam parcialmente substituir-se uns aos outros. Este fato explica o que acontece no "ácido coleico natural", onde, como é sabido, encontram-se ácido esteárico, palmítico e oleico em proporções variaveis, embora a composição do composto se mantenha sempre na proporção de uma molécula de ácido graxo para oito de ácido desoxicólico.

Das nossas experiências tambem se conclue que os compostos moleculares do ácido apocólico devem possuir uma construção cristalina análoga à dos ácidos coleicos propriamente ditos.

A nosso ver, na isomorfia dos ácidos desoxicólico e apocólico reside a explicação do fato pelo qual, dentre todos os ácidos biliares específicos examinados até hoje, naturais ou artificiais, o ácido apocólico é o único capaz de formar compostos moleculares do tipo dos ácidos coleicos.

\section{PARTE EXPERIMENTAL}

Como já foi dito, a possibilidade da formação de cristais mistos, entre os diversos compostos estudados, foi examinada por meio dá análise térmica dos sistemas binários.

Adotou-se o "Método de clegêlo-fusão" ("Auftau-Schmelz-methode") creado por H. Rhernboldt para a determinação de diagramas de estado, principalmente de sistemas orgânicos. ${ }^{25}$ )

O Autor faz uso das expressões: degelar ("auftauen") o ponto de degêlo ("Auftaupunkt") afim de poder distinguir o ponto inicial do ponto final do fenômeno da passagem de uma mistura de substâncias do estado sólido para o líquido. O ponto de degêlo corresponde à temperatura em que uma mistura sólida começa a liquefazer-se e é caraterizado pelo aparecimento das primeiras gotículas de líquido. Diz-se que a essa temperatura a substância degela. O ponto de fusão corresponde à temperatura em que desaparecem os últimos cristaizinhos contidos na fase líquida. Diz-se que a essa temperatura a substância funde.

Abaixo do ponto de degêlo existem, pois, somente fases sólidas e acima do ponto de fusão somente fases líquidas ; entre esses dois pontos ha coe-

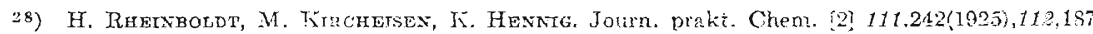
(i926),113,199 e $348(1926)$ : C.1926.1. 2069.2873,1926.I1.1113,2031.: Chem Abstr. 20,693 ; 20,1938 ; $21 j, 3120 ; 21,14$. 
xistência de fases sólidas e líquidas. Os pontos de degêlo e de fusão de uma substância pura são praticamente coincidentes. - Nos sistemas binários a cada composição correspondem determinados pontos de degêlo e de fusão. Os diversos pontos de degêlo e de fusão de diversas composições formam, reunidos, o diagrama de estado do sistema. - Foi provado, por meio de muitos exemplos, que nos sistemas binários os pontos de fusão correspondem exatamente aos pontos da "cristalização primária" e os de degêlo aos da "cristalização secundária" do método clássico.

Quando duas substâncias não formam um composto químico nem cristais mistos entre si, mas somente um conglomerado sólido, o "Diagrama de degêlo-fusão" mostra três pontos distintos em que as constantes de degêlo e fusão se tornam idênticas, isto é, nos pontos correspondentes à concentração das duas substâncias puras e à da mistura eutética. A curva dos pontos de fusão do diagrama consiste, neste caso, de dois ramos que se intersectam no ponto eutético, pela qual passa a linha do eutético paralela ao eixo das composições (abcissas), que atravessa todo o diagrama e que é formada pelos pontos de degêlo. Quando duas substâncias formam um composto químico estável o "Diagrama de degêlo-fusão" mostra cinco pontos distintos nos quais ha coincidência dos pontos de degêlo e de fusão: nas concentrações das substâncias puras, na do composto e nas das duas misturas eutéticas que o composto forma, de um lado com uma, e do outro lado com a outra das substâncias puras. A curva dos pontos de fusão do diagrama consiste de três ramos que se intersectam em dois pontos eutéticos, sendo que o ramo médio da curva atinge um maximo no lugar correspondente à composição do composto. Os pontos de degêlo formam duas linhas horizontais eutéticas. - Nos casos de formação de cristais mistos foi provado que a curva dos pontos de fusão corresponde exatamente à curva "liquidus" e a dos pontos de degêlo à curva "solidus" do método clássico. No tipo I dos diagramas de séries contínuas de cristais mistos ha sempre, em todas as misturas possíveis, um certo intervalo entre o ponto de degêlo e o de fusão, e estes pontos se acham sempre entre os das substâncias puras. No tipo II (muito raro) ambas as curvas são côncavas e no tipo III convexas, em relação ao eixo das concentrações do diagrama, e no caso ideal existe um ponto de concentração em que as duas curvas se tocam.

A execução prática do "Método de degêlo-fusão" consiste no seguinte : Prepara-se uma série de misturas das substâncias simples em proporção progressiva, em tubinhos de vidro ou em pequenas capsulas de porcelana, por meio de cuidadosa fusão conjunta; mistura-se bem o líquido, e após completa solidificação num dessecador passa-se quantitativamente a massa para um gral de ágata e tritura-se cuidadosamente. Si for possível fazer a fusão num cadinho faz-se a trituração no mesmo. Pequenas amostras de cada mistura, pulverizada e novamente secada em dessecador, são colocadas em tubinhos de vidro de ca. $2 \mathrm{~mm}$ de diametro nos quais se introduz uma pequena vareta de vidro ou de platina. Os tubinhos são levados 
a um banho de aquecimento apropriado. Para conseguir resultados exatos deve-se ter o cuidado de manter o aquecimento sempre muito regular e vagaroso. Controla-se o comportamento da substância por meio de uma lente e com iluminação elétrica lateral. Determina-se, em primeiro lugar, o ponto de degêlo ; ultrapassado este, continua-se a aquecer lentamente e mistura-se o conteudo dos tubinhos cuidadosamente com a vareta afim de estabelecer um perfeito equilíbrio entre as fases sólida e líquida. - Tendose à disposição um microscópio de aquecimento, de preferência um de polarização, a execução das determinações é bastante simplificada e aperfeiçoada.

Eiste método é hoje o mais usado na determinação de diagramas de estado de substâncias orgânicas. - Já se elevam a várias centenas os sistemas cujos diagramas foram obtidos por este processo. Foi somente depois da creação deste novo método que se tornou possível um maior desenvolvimento da pesquisa de sistemas binários orgânicos, e este fato encontra sua explicação em diversos motivos. - Na maneira usual de proceder, cada ponto de um diagrama requer cerca de 0,lg da mistura das substâncias, isto é, cerca de um trigésimo a um vigésimo da quantidade necessária no método clássico do resfriamento da solução, de maneira que se necessita para a determinação de um sistema completo de menos substância do que é preciso para a determinação de um único ponto, segundo o método anterior. Alem disso, Rheinboldt estabeleceu o "método de degêlo-fusão" tamben para micro determinações, de modo que o gasto fica reduzido a alguns miligramas de substância. Devido ao pequeno calor de cristalização e à fraca condutibilidade calorífica das substâncias orgânicas, o método clássico da análise térmica, creado para o estudo de misturas de metais, não pôde ser aplicado nesse ramo com igual sucesso. - Com efeito, os pesquisadores que o adotaram obtiveram, na grande maioria dos casos, somente a curva da primeira cristalização e não a da cristalização eutética ou a curva "solidus", fato que naturalmente privou o método da sua grande precisão e conduziu muitas vezes a erros. O novo método quanto à sua exatidão é equivalente ao clássico, quando este apresenta ambas as curvas. - Não existindo na fusão, ao contrário do que acontece na solidificação, fenômenos de transgressão, muito comuns nas substâncias orgânicas, o novo método não é influenciado por tais dificuldades e os diversos pontos de degêlo e de fusão se ordenam em curvas muito regulares. Mesmo em casos em que uma mistura de substâncias não pode ser fundida ou mantida nesse estado por algum tempo devido à fácil decomposição, o "método de degêlo-fusão" é ainda aplicável com certas cautelas.

Várias das substâncias examinadas no nosso trabalho encontram-se neste caso. As misturas não podem por isso ser preparadas por meio de fusão completa dos componentes, sendo então recomendável uma fusão parcial dos mesmos. Âs vezes não é possivel adotar nem mesmo este último processo. Prepara-se então a mistura por meio de uma simples mas íntima 
trituração das substâncias componentes, nas proprias capsulas em que foram pesadas. Esses últimos métodos não são tão seguros como o da fusão completa dos componentes, mas repetindo-se as determinações dos pontos de degêlo e de fusão de cada mistura com várias amostras, chega-se igualmente a resultados satisfatórios.

Os ácidos coleicos foram preparados segundo as indicações da literatura original.

Os ácidos desoxicólico e apocólico usados pertenciam a uma coleção de substâncias de propriedade do Prof. Dr. Heinrich Rheinboldt.

A fenantrena e a acenaftena utilizadas em algumas experiências do nosso trabalho, nos foram muito gentilmente remetidas da Itália pelo Prof. Dr. Bernardo Oddo, da Universidade de Pavia, por intermédio do Prof. Dr. Quintino Mingoja, diretor químico do Laboratório Paulista de Biologia. Ao Prof. Oddo e ao Prof. Mingoja os nossos sinceros agradecimentos. 


\section{PRIMEIRA PARTE}

\section{Sistemas binários de ácidos coleicos.}

Manteve-se em todos os casos um aquecimento vagaroso, com a velocidade aproximada de 2 minutos por gráu nas proximidades dos pontos de degêlo e de fusão.

Os tubinhos com as misturas foram geralmente introduzidos no banho de aquecimento a temperaturas inferiores de 10 a $15^{\circ}$ às correspondentes aos respetivos pontos de degêlo ou de fusão.

1. Sistema : Ácido esteárico-coleico (1:8)+ácido palmítico-coleico (1:8).

\section{Fig. III,1).}

Preparą̧ão do ácido esteárico-coleico $(1: 8) .{ }^{29}$ ) O ácido esteárico ("KCahlbaum Schering" - Berlim) foi recristalizado diversas vezes de alcool absoluto atế apresentar o P.F. $=68,8-70^{\circ}$

Dissolveram-se em cerca de $8 \mathrm{~cm}^{3}$ de alcool absoluto quente, $2 \mathrm{~g}$ de ácido desoxicólico e juntaram-se, a seguir, a esta soluçãa, 0,2g de ácido estéárico puro. Separou-se, ao resfriar, um produto que, após recristalização de alcool absoluto e secagem no alto vácuo a ca. $80^{\circ}$, apresentava o P.F. $=186-187^{\circ}$.

Preparação do ácido palmítico-coleico $(\mathbf{1 : 8}) .{ }^{30}$ ) O ácido palmítico (Gehe \& Cia. - Dresden), purissimo, foi recristalizado uma vez de alcool absoluto. P.F. $=63-64^{\circ}$.

2g de ácido desoxicólico e 0,2g de ácido palmítico foram dissolvidos em ea. $8 \mathrm{~cm}^{3}$ de alcool absoluto quente. Ponto de fusão do produto: 184-185.

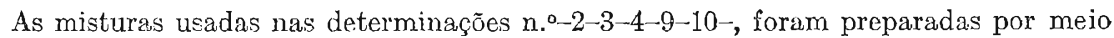
de fusão parcial dos componentes em pequenas capsulas de porcelana e, a seguir, cuidadosamente trituradas em gral de ágata. As misturas usadas nass experiências $n^{\circ}-5-6-7-8-$, foram obtidas simplesmente por trituração dos componentes.

$29)$ H. Wreland e H. Sorge, Ztschr. physiol. Chem. 97,19-20(1916), P. F. $=186-187$.

H. Rheingoldt, Ann. 451,268(1927). - P.F. $=186-187^{\circ}$

Sistema binário: Ac esté́ricotac desoxicólico - H. Rheinzordr, Ztschr. physiol. Chem. 180,183(1929) - - Máximo da curva de fusão $=185^{\circ}$; composto $1: 8$ de fusão homogenea e de enorme território de estabilidade, entre 1 e $99 \%$ em peso de ac. desoxicólico.

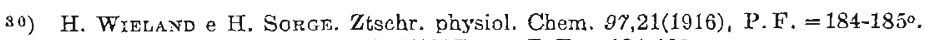

H. Rhmingoldt. Ann. 451,267(1927) - P.F. $=184-185^{\circ}$.

H. Rrembondt. Ztscht. physiol. Chem 180,181(1929), Sistema binário: Ac. oalmíticotac. desoxicólico. Máximo da curva de fusão: 1840; pontos eutéticos : 60\%1\% e 164\%/99\% em peso de ac. desoxicólico. 
Os pontos de degêlo e ảe fusão de cada mistura foram determinados em amostras separadas.

\begin{tabular}{|c|c|c|c|c|c|}
\hline N. ${ }^{\circ}$ & $\begin{array}{l}\text { I. Ac. pamitico- } \\
\text { coleico } g\end{array}$ & $\begin{array}{l}\text { II. Ac, esteárico- } \\
\text { coleico } \mathrm{g}\end{array}$ & $\begin{array}{c}\text { \%em peso } \\
\text { II }\end{array}$ & P.D. ${ }^{\circ} \mathrm{C}$. & P.F. ${ }^{\circ} \mathrm{C}$. \\
\hline $\begin{array}{r}1 \\
2 \\
3 \\
4 \\
5 \\
6 \\
7 \\
8 \\
9 \\
10 \\
11\end{array}$ & $\begin{array}{c}-\overline{0,0956} \\
0,0822 \\
0,0733 \\
0,0601 \\
0,0526 \\
0,0415 \\
0,0330 \\
0,0251 \\
0,0128 \\
\ldots\end{array}$ & $\begin{array}{c}-\overrightarrow{0} \\
0,0098 \\
0,0183 \\
0,0261 \\
0,0438 \\
0,0530 \\
0,0623 \\
0,0648 \\
0,0847 \\
0,1019 \\
-\end{array}$ & $\begin{array}{r}0,0 \\
9,3 \\
18,2 \\
26,3 \\
42,2 \\
50,2 \\
60,0 \\
66,3 \\
77,1 \\
88,8 \\
100,0\end{array}$ & $\begin{array}{l}184,0 \\
184,0 \\
184,0 \\
184,0 \\
184,0 \\
184,0 \\
184,0 \\
184,0 \\
185,0 \\
185,0 \\
186,0\end{array}$ & $\begin{array}{l}185,0 \\
185,5 \\
187,0 \\
187,0 \\
187,0 \\
187,0 \\
187,2 \\
187,0 \\
187,0 \\
187,2 \\
187,0\end{array}$ \\
\hline
\end{tabular}

Os componentes formam uma série contúna de cristais mistos do tipo $I$,

2. Sistema : Ácido esteárico-coleico $(\mathbf{l}: 8)$ + ácido mixístico-coleico ( $1: 6$ ) Fig, III, 2).

Preparaşão do ácido mirístico-coleico $(1: 6) .{ }^{31}$ ) O acido miŕstico (Dr. Theodor Schuchardt. - Goerlitz) foi purificado por meio de diversas recristalizaçôes de alcool absoluto. P.F. $=52,5-53,5^{\circ}$.

Dissolveram-se $4 \mathrm{~g}$ de ácido desoxicólico e $0,3 \mathrm{~g}$ de ácido miŕstico em $8-10 \mathrm{~cm}^{3}$ de alcool absoluto quente. P.F. do produto separado por cristalização: 181-1820

Todas as misturas foram preparadas por meio de íntima trituração das substâncias componentes.

Os pontos de degêlo e de fusão de cada mistura foram determinados nas mesma. amostras.

\begin{tabular}{|r|c|c|c|c|c|}
\hline N. & \multirow{2}{*}{$\begin{array}{c}\text { I. Ac. láurico- } \\
\text { coleico }\end{array}$} & II. Ac. esteárico- & \% em peso & P. D. o C. & P.F. ${ }^{\circ}$ C. \\
\hline 1 & & & & & \\
\hline 2 & 0,0905 & - & 0,0 & 181,0 & 182,0 \\
3 & 0,0836 & 0,0099 & 9,9 & 181,0 & 183,8 \\
4 & 0,0864 & 0,0179 & 17,6 & 181,5 & 184,2 \\
5 & 0,0714 & 0,0276 & 24,2 & 182,0 & 184,4 \\
6 & 0,0608 & 0,0311 & 30,3 & 182,0 & 185,0 \\
7 & 0,0581 & 0,0418 & 40,2 & 182,4 & 185,2 \\
8 & 0,0442 & 0,0586 & 50,2 & 183,0 & 185,5 \\
9 & 0,0502 & 0,0655 & 59,7 & 183,2 & 186,0 \\
10 & 0,0227 & 0,1016 & 66,9 & 183,8 & 186,4 \\
11 & 0,0104 & 0,0815 & 78,2 & 184,5 & 186,8 \\
12 & - & 0,0858 & 89,2 & 185,0 & 187,0 \\
& & - & 100,0 & 186,0 & 187,0 \\
\hline
\end{tabular}

Os componentes do sistema formam una série contínua de cristais mistos do tipo I.

31) H. Rheinboldt. Ann. 451,266(1927) - P.F. $=181-182^{\circ}$. 
3. Sistema : Ácido esteárico-coleico $(1: 8)$ +ácido láurico-coleico $(1: 6)$ Fig. III, 3).

Preparação do ácido láurico-coleico (1:6). ${ }^{32} \mathrm{O}$ ácido láurico (Dr. Theodor Schuchardt - Goerlitz) foi purificado por meio de recristalizações de alcool absoluto. P.F. = $=42-43,5^{\circ}$.

Dissolveram-se em ca. $10 \mathrm{~cm}^{3}$ de alcool absoluto quente, $4 \mathrm{~g}$ de ácido desoxicólico puro e $0,25 \mathrm{~g}$ de ácido láurico. P.F. do produto separado por cristalização: $176,5-177,5^{\circ}$.

Todas as misturas foram preparadas por meio de intima trituração dos componentes.

Os pontos de degêlo e de fusão de cada mistura foram sempre determinados nas mesmas amostras.

O diagrama de estado desse sistema mostra uma série contínuà de cristais mistos do tipo $\mathrm{I}$.

\begin{tabular}{|c|c|c|c|c|c|}
\hline N.o & $\begin{array}{l}\text { I. Ac. láurico- } \\
\text { coleico g }\end{array}$ & $\begin{array}{l}\text { II. Ac. esteárico- } \\
\text { coleico } \mathrm{g}\end{array}$ & $\begin{array}{l}\text { \%em peso } \\
\text { II }\end{array}$ & P.D. ${ }^{\circ} \mathrm{C}$. & P.F. C. \\
\hline $\begin{array}{r}1 \\
2 \\
3 \\
4 \\
5 \\
6 \\
7 \\
8 \\
9 \\
10 \\
11\end{array}$ & $\begin{array}{c}\overline{-} \\
0,0912 \\
0,0817 \\
0,0687 \\
0,0641 \\
0,0515 \\
0,0424 \\
0,0308 \\
0,0210 \\
0,0102 \\
-\end{array}$ & $\begin{array}{c}\overline{0}, 0125 \\
0,0206 \\
0,0323 \\
0,0475 \\
0,0524 \\
0,0696 \\
0,0738 \\
0,0802 \\
0,0918 \\
-\end{array}$ & $\begin{array}{r}0,0 \\
12,0 \\
20,1 \\
32,0 \\
42,6 \\
50,4 \\
62,1 \\
70,6 \\
79,2 \\
90,0 \\
100,0\end{array}$ & $\begin{array}{l}176, \tilde{5} \\
176,5 \\
176,5 \\
177,0 \\
178,0 \\
178,5 \\
180,6 \\
181,2 \\
182,8 \\
184,2 \\
186,0\end{array}$ & $\begin{array}{l}177,5 \\
179,4 \\
180,5 \\
181,4 \\
182,4 \\
183,8 \\
184,2 \\
185,0 \\
186,0 \\
186,6 \\
187,0\end{array}$ \\
\hline
\end{tabular}

4. Sistema : Âcido araquídico-coleico $(1: 8)$ +ácido láurico-coleico $(1: 6)$

Fig. III, 4).

Preparação do ácido araquídico-coleico $\left.(\mathbf{1 : 8}){ }^{33}\right) \quad \mathrm{g}$ de ácido desoxicólico e $0,2 \mathrm{~g}$ de ácido araquídico (P.F.74 ${ }^{\circ}$ ) foram dissolvidos em $8 \mathrm{~cm}^{3}$ de alcool absoluto quente. Separou-se, ao resfriar, um produto que, após recristalização de alcool absoluto e secagem no alto vácuo a $80^{\circ}$, apresentava o P.F. $=189,5-190,5 .^{\circ}$.

32) H. Rheinboldx. Ann. 4501,266(1927) - P.F. $=176-177^{\circ}$.

33) H. Rheinboldt. Ann. $451,269(1927)$. - P. F. $=188-1890^{\circ}$. 


\begin{tabular}{|c|c|c|c|c|c|c|}
\hline Y.o & $\begin{array}{l}\text { I. Ac. láurico- } \\
\text { coleico g }\end{array}$ & II. & $\begin{array}{l}\text { Ac. araquídico- } \\
\text { coleico } \mathrm{g}\end{array}$ & $\begin{array}{c}\% \text { em peso } \\
\text { II }\end{array}$ & P.D. ${ }^{\circ} \mathrm{C}$. & P.F. ${ }^{\circ}$. \\
\hline $\begin{array}{r}1 \\
2 \\
3 \\
4 \\
5 \\
6 \\
7 \\
8 \\
9 \\
10 \\
11\end{array}$ & $\begin{array}{c}-\overline{0,0916} \\
0,0802 \\
0,0718 \\
0,0603 \\
0,0498 \\
0,0384 \\
0,0309 \\
0,0210 \\
0,0110 \\
-\end{array}$ & & $\begin{array}{c}-\overline{0,0100} \\
0,0216 \\
0,0334 \\
0,0428 \\
0,0501 \\
0,0625 \\
0,0813 \\
0,0856 \\
0,0946 \\
-\end{array}$ & $\begin{array}{r}0,0 \\
9,8 \\
21,2 \\
31,7 \\
41,5 \\
50,1 \\
61,9 \\
72,5 \\
80,3 \\
89,6 \\
100,0\end{array}$ & $\begin{array}{l}176,5 \\
176,5 \\
177,0 \\
178,5 \\
179,0 \\
181,0 \\
183,0 \\
184,0 \\
187,0 \\
188,0 \\
189,5\end{array}$ & $\begin{array}{l}177,5 \\
180,5 \\
182,2 \\
185,0 \\
185,2 \\
186,5 \\
187,5 \\
188,2 \\
190,2 \\
190,4 \\
190,5\end{array}$ \\
\hline
\end{tabular}

As misturas foram todas preparadas por meio de cuidadosa trituração das substân(ias componentes.

Os pontos de degêlo e de fusão de cada mistura foram sempre determinados nas mesmas amostras.

Os componentes formam uma série contínua de cristais mistos do tipo I.

5. Sistema: Ácido esteárico-coleico $(1: 8)$ +ácido naftalena-coleico $(1: 2)$ Fig. IV,1).

Preparação do ácido naftalena-coleico $\left.(1: 2) .{ }^{34}\right)$ A naftalena foi purificada por recristalização de alcool absoluto. P.F. $=79-80^{\circ}$.

Dissolveram-se $2 \mathrm{~g}$ de ácido desoxicólico em $\mathrm{ca.} 8 \mathrm{~cm}^{3}$ de alcool absoluto quente e juntaram-se, a seguir, $0,25 \mathrm{~g}$ de naftalena. O produto separado por cristalização fundia a $181,5-182,5 .{ }^{\circ}$.

\begin{tabular}{|c|c|c|c|c|c|}
\hline N.o & $\begin{array}{l}\text { 1. Ac. naftalena- } \\
\text { coleico g }\end{array}$ & $\begin{array}{l}\text { II. Ac. esteárico- } \\
\text { coleico g }\end{array}$ & $\begin{array}{l}\text { \%em peso } \\
\text { II }\end{array}$ & P.D. ${ }^{\circ} \mathrm{C}$ & P.F. ${ }^{\circ} \mathrm{C}$ \\
\hline $\begin{array}{r}1 \\
2 \\
3 \\
4 \\
5 \\
6 \\
7 \\
8 \\
9 \\
10 \\
11 \\
12 \\
13\end{array}$ & $\begin{array}{c}\overline{0} \\
0,1067 \\
0,0787 \\
0,0698 \\
0,0606 \\
0,0504 \\
0,0325 \\
0,0400 \\
0,0300 \\
0,0240 \\
0,0144 \\
0,0086\end{array}$ & $\begin{array}{c}\overline{-} \\
0,0131 \\
0,0185 \\
0,0302 \\
0,0370 \\
0,0411 \\
0,0333 \\
0,0618 \\
0,0716 \\
0,0784 \\
0,0858 \\
0,0926\end{array}$ & $\begin{array}{r}0,0 \\
10,9 \\
19,0 \\
30,2 \\
37,9 \\
44,9 \\
50,6 \\
60,7 \\
70,5 \\
76,6 \\
85,6 \\
91,5 \\
100,0\end{array}$ & $\begin{array}{l}181,5 \\
178,8 \\
177,0 \\
174,0 \\
174,5 \\
173,0 \\
173,4 \\
174,5 \\
175,0 \\
176,5 \\
178,0 \\
180,0 \\
186,0\end{array}$ & $\begin{array}{l}182,5 \\
181,6 \\
181,5 \\
179,0 \\
179,0 \\
180,0 \\
180,6 \\
181,0 \\
182,2 \\
183,2 \\
185,0 \\
185,6 \\
187,0\end{array}$ \\
\hline
\end{tabular}

34) H. Wieland e H. Sorge. Ztschr. physiol. Chem. 97,24(1916). FF. 182。.

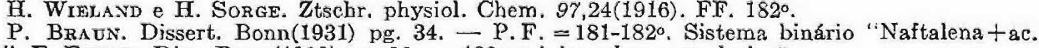
desoxicólico". E. Flume, Diss. Bonn(1929) pg. 26. - $182^{\circ}$ máximo da curva de fusão. 
As misturas foram preparadas por meio de íntima trituração das substâncias em pequenas capsulas de porcelana. Algumas determinações, executadas com misturas obtidas por meio de fusão dos componentes, forneceram resultados diferentes, notando-se no diagrama um intervalo de temperatura demasiado grande entre as curvas "solidus" e "liquidus".

O ponto de degêlo e o de fusão de cada mistura foram sempre determinados em amostras diferentes.

Os componentes formam uma série contínua de cristais mistos passando as curvas por um mínimo.

\section{Sistema : Ácido esteárico-coleico $(1: 8)+$ ácido antracena-coleico (1:4)}

Fig. IV,2).

Preparação do ácido antracena-coleico. $(1: 4).)^{35}$ A antracena, obtida pela extrnção de um produto técnico (E. Merck - Darmstadt -) com alcool comum, foi purificada por meio de várias recristalizações de uma mistura de alcool absoluto e benzena pura $(1: 1)$. P.F. $=214-215,5^{\circ}$

Dissolveram-se $2 \mathrm{~g}$ de ácido desoxicólico em ca. $6 \mathrm{~cm}^{3}$ de alcool absoluto quente e it solução formada juntaram-se $0,2 \mathrm{~g}$ de antracena. A seguir foram adicionadas algumas gotas de benzena em quantidade apenas suficiente para conseguir a dissolução da antracena. Ao restriar separou-se um produto cristalino de P.F. $=189,5-192^{\circ}$.

\begin{tabular}{|c|c|c|c|c|c|}
\hline Nio & $\begin{array}{l}\text { I. Ac. esteárico- } \\
\text { coleico } \mathrm{g}\end{array}$ & $\begin{array}{l}\text { II. Ac. antracena- } \\
\text { coleico g }\end{array}$ & II & P.D. ${ }^{\circ} \mathrm{C}$. & P.F. ${ }^{\circ} \mathrm{C}$. \\
\hline $\begin{array}{r}1 \\
2 \\
3 \\
4 \\
5 \\
6 \\
7 \\
8 \\
9 \\
10 \\
11 \\
12\end{array}$ & $\begin{array}{c}- \\
0,0966 \\
0,1045 \\
0,0749 \\
0,0635 \\
0,0613 \\
0,0526 \\
0,0422 \\
0,0301 \\
0,0148 \\
0,0064 \\
-\end{array}$ & $\begin{array}{c}-\overline{0} \\
0,0108 \\
0,0225 \\
0,0248 \\
0,0316 \\
0,0436 \\
0,0528 \\
0,0655 \\
0,0711 \\
0,0757 \\
0,0969 \\
-\end{array}$ & $\begin{array}{r}0,0 \\
10,1 \\
17,7 \\
24,9 \\
33,2 \\
41,6 \\
50,0 \\
60,8 \\
73,3 \\
83,6 \\
93,8 \\
100,0\end{array}$ & $\begin{array}{l}186,0 \\
184,8 \\
184,8 \\
184,5 \\
184,0 \\
183,8 \\
183,2 \\
183,0 \\
183,5 \\
185,0 \\
187,5 \\
189,5\end{array}$ & $\begin{array}{l}187,0 \\
186,0 \\
186,0 \\
186,0 \\
185,8 \\
186,0 \\
186,5 \\
188,0 \\
189,0 \\
190,0 \\
191,0 \\
192,0\end{array}$ \\
\hline
\end{tabular}

As misturas usadas nas determinações $\mathrm{n}^{\circ}-2-3-9-10$ - foram preparadas por meio de fusão parcial dos componentes, as demais, por simples trituração.

Os pontos de degêlo e de fusão de cada mistura foram determinados sempre nas mesmas amostras.

Os componentes formam uma série contínua de cristais mistos. As curvas passam por um mínimo.

35) W. Marx e H. Soвotza. Journ. Organic Chem. I,277(1936). Chem. Abstr. $\$ 1,1033$. C.1987. I. 2982. - 1:4. P.F. $=193^{\circ}$ (corr.) 
7. Sistema : Ácido esteárico-coleico $(1: 8)$ + ácido fenantrena-coleico $(1: 3)$

Fig. IV,3).

Preparação do ácido fenantrena-coleico $(1: 3) .^{36}$, A uma solução quente de $1,5 \dot{g}$ le ácido desoxicólico en ca.8 $\mathrm{cm}^{3}$ de alcool absolito, juntaram-se $0,2 \mathrm{~g}$ de fenantrena. (P.F.97-98\%). Ao resfriar separou-se um produto de P.F. $=181-186^{\circ}$.

\begin{tabular}{|c|c|c|c|c|c|}
\hline$\therefore . "$ & $\begin{array}{l}\text { 1. Ac. fenantrena- } \\
\text { coleico } \mathrm{g}\end{array}$ & $\begin{array}{l}\text { II. Ac. esteárico- } \\
\text { coleico g } \mathrm{g}\end{array}$ & $\begin{array}{c}\text { \%om peso } \\
\text { II }\end{array}$ & P D. ${ }^{\circ} \mathrm{C}$. & P.F. ${ }^{\circ}$. \\
\hline 1 & - & - & 0,0 & 184,0 & 186,0 \\
\hline 2 & 0,0886 & 0,0084 & 8,7 & 181,5 & 185,2 \\
\hline 3 & 0,0807 & 0,0215 & 21,0 & 180,0 & 184,4 \\
\hline$t$ & 0,0672 & 0,0328 & 32,8 & 179,5 & 183,2 \\
\hline $\bar{j}$ & 0,0639 & 0,0423 & 39,8 & 179,0 & 182,6 \\
\hline 6 & 0,0544 & 0,0424 & 43,8 & 179,0 & 182,6 \\
\hline 7 & 0,0516 & 0,0574 & 52,7 & 178,6 & 183,2 \\
\hline$\oint$ & 0,0371 & 0,0635 & 63,1 & 178,6 & 183,6 \\
\hline 9 & 0,0307 & 0,0719 & 70,1 & 179,0 & 184,4 \\
\hline 10 & 0,0211 & 0,0832 & 79,8 & 180,0 & 185,2 \\
\hline 11 & $0,011 \frac{1}{1}$ & 0,1107 & 90,7 & 181,5 & 186,4 \\
\hline 12 & 0,0053 & 0,0963 & 94,8 & 182,5 & 186,8 \\
\hline 13 & - & - & 100,0 & 186,0 & 187,0 \\
\hline
\end{tabular}

Todas as misturas foram preparadas por meio de ìntima trituração das substâncias componentes.

Os pontos de degêlo e de fusão foram sempre determinados nas mesmas amostras.

Os componentes formam uma série contínua de cristais mistos. As curvas passam por um mínimo.

8. Sistema : Ácido esteárico-coleico $(1: 8)$ + ácido acenaftena-coleico $(1: 2)$. Fig. IV,4).

Preparação do ácido acenaftena-coleico $(\mathbf{1}: 2) .{ }^{37}$ ) $2 \mathrm{~g}$ de ácido desoxjcólico e $0,4 \mathrm{~g}$ de acenaftena $\left(\mathrm{P} . \mathrm{F} .=93-95^{\circ}\right.$ ) foram dissolvidos em $\mathrm{ca} .8 \mathrm{~cm}^{3}$ de alcool absoluto quente. Ao resfriar separou-se um produto de P.F. $=174,5-176,5$.

ib) L. Finger e M. S. Newian. Am. Chem. Soc. $\overline{0} \%, 1602(1935)$; C. 1935. II. 24.; Chem. Abstr. 20,7341 . - P.F. $=184-185^{\circ}$. (corr.)

Wr. MARE ? H. SobotKa. 1.c. - P.F. 186-1870(corr.)

37j L. Fieser e M. S. Nevinan. Am. Chem. Soc. 57,1602(1935); C.1955.1I.24.; Chem. Abstr. $29,7341-P . F \cdot=175,5-176,5 \cdot 0^{\circ}$ (corr.) 


\begin{tabular}{|c|c|c|c|c|c|}
\hline N. ${ }^{\circ}$ & $\begin{array}{l}\text { I. Ac. acenaftena- } \\
\text { coleico } g\end{array}$ & $\begin{array}{l}\text { II. Ac. esteárico- } \\
\text { coleico g }\end{array}$ & $\begin{array}{c}\text { \%em peso } \\
\text { II }\end{array}$ & P.D. ${ }^{\circ} \mathrm{C}$ & P.F. ${ }^{\circ}$ C. \\
\hline 1 & - & $\ldots$ & 0,0 & 174,5 & $176, \tilde{\delta}$ \\
\hline 2 & 0,0931 & 0,0080 & 7,9 & $172, \overline{5}$ & 176,0 \\
\hline 3 & 0,0695 & 0,0132 & 16,0 & 171,5 & 175,4 \\
\hline 4 & 0,0618 & 0,0150 & 19,5 & 172,4 & 175,5 \\
\hline 5 & 0,0770 & 0,0258 & 25,1 & 172,2 & 175,8 \\
\hline 6 & 0,0500 & 0,0224 & 30,9 & 172,0 & 176,4 \\
\hline 7 & 0,0400 & 0,0280 & 41,2 & $171, \check{5}$ & $177, \overline{5}$ \\
\hline 8 & 0,0485 & 0,0520 & 51,7 & 171,5 & 178,6 \\
\hline 9 & 0,0300 & 0,0479 & 61,5 & 171,2 & 180,5 \\
\hline 10 & 0,0347 & 0,0668 & 65,8 & $171, \overline{0}$ & 181,0 \\
\hline 11 & 0,0300 & 0,0892 & 74,8 & 171,5 & 182,6 \\
\hline 12 & 0,0199 & 0,0883 & 81,6 & 172,0 & 183,6 \\
\hline 13 & 0,0127 & 0,0886 & 87,5 & $172, \overline{0}$ & 181,0 \\
\hline 14 & 0.0075 & $0,092 \overline{5}$ & 92,5 & $17 \overline{0} . \overline{0}$ & 185,4 \\
\hline 15 & - & - & 100,0 & 186,0 & 187,0 \\
\hline
\end{tabular}

As misturas foram preparadas por meio de íntima trituração dos componentes.

Todas as misturas adquirem ao fundir, uma coloração amarela, tanto mais intensia quanto maior a porcentagem de ácido aceraftena-coleico.

Os pontos de degêlo e de fusão de cada mistura foram determinados sempre nas mesmas amostras.

Os componentes formam uma série contínua de cristais mistos. ${ }^{35}$ )

9. Sistena: Ácido naftalena-coleico $(1: 2)+$ ácido antracena-coleico $(1: 4$ : Fig. $V, 1$ ).

Todas as misturas foram preparadas por meio de intima trituração das substânciass componentes.

Os pontos de degêlo e de fusão de cada mistura foram sempre determinados nas mesmas amostras.

38) A forma singular da curva. "solidus" confere ao diagrama deste sistema um aspeto diferente do dos três casos precedentes, Devido porem ds dificuldades encontradas nas determinaçōes dos pontos de degêlo, atribuíveis à natureza da substância, não podemos levar em grande considerasão, neste caso, esses. valores e por isso as nosstas conclusöes baseiam-se principalmente no comportamento da curva "liquidus." 
Os componentes formam uma série contínua de cristais mixtos do tipo I.

\begin{tabular}{|c|c|c|c|c|c|}
\hline N. ${ }^{\circ}$ & $\begin{array}{l}\text { I. Ac. naftalena- } \\
\text { coleico g }\end{array}$ & $\begin{array}{l}\text { II. Ac. antracena- } \\
\text { coleico g }\end{array}$ & \%em peso & P.D. ${ }^{\circ} \mathrm{C}$. & P.F. ${ }^{\circ}$ C. \\
\hline $\begin{array}{r}1 \\
2 \\
3 \\
4 \\
5 \\
6 \\
7 \\
8 \\
9 \\
10 \\
11\end{array}$ & $\begin{array}{c}-\overline{0} \mathbf{0 9 1 9} \\
0,0882 \\
0,0712 \\
0,0625 \\
0,0513 \\
0,0423 \\
0,0293 \\
0,0215 \\
0,0106 \\
-\end{array}$ & $\begin{array}{c}-\overline{0} \\
0,0089 \\
0,0211 \\
0,0312 \\
0,0466 \\
0,0570 \\
0,0647 \\
0,0701 \\
0,0814 \\
0,0906 \\
-\end{array}$ & $\begin{array}{r}0,0 \\
8,8 \\
19,3 \\
30,5 \\
42,7 \\
52,6 \\
60,5 \\
70,5 \\
79,1 \\
89,5 \\
100,0\end{array}$ & $\begin{array}{l}181,0 \\
182,2 \\
182,5 \\
183,0 \\
183,8 \\
184,2 \\
185,0 \\
185,5 \\
186,4 \\
186,5 \\
189,0\end{array}$ & $\begin{array}{l}182,0 \\
183,8 \\
184,5 \\
185,0 \\
186,2 \\
186,4 \\
187,0 \\
188,2 \\
188,8 \\
189,5 \\
191,0\end{array}$ \\
\hline
\end{tabular}

10. Sistema : Ácido naftalena-coleico $(1: 2)$ - ácido fenantrena-coleico $(1: 3)$

Fig. $V, 2)$.

\begin{tabular}{|c|c|c|c|c|c|}
\hline N. ${ }^{\circ}$ & $\begin{array}{l}\text { I. Ac. naitalena- } \\
\text { coleico } \mathrm{g}\end{array}$ & $\begin{array}{l}\text { II. Ac. fenantrena- } \\
\text { colcico g }\end{array}$ & $\begin{array}{l}\text { \%em peso } \\
\text { II }\end{array}$ & P.D. ${ }^{\circ} \mathrm{C}$. & P.F. ${ }^{\circ} \mathrm{C}$. \\
\hline $\begin{array}{r}1 \\
2 \\
3 \\
4 \\
5 \\
6 \\
7 \\
8 \\
9 \\
10 \\
11 \\
12\end{array}$ & $\begin{array}{c}\overline{0} 1013 \\
0,0634 \\
0,0767 \\
0,0682 \\
0,0370 \\
0,0484 \\
0,0378 \\
0,0273 \\
0,0130 \\
0,0068 \\
-\end{array}$ & $\begin{array}{c}- \\
0,0070 \\
0,0100 \\
0,0214 \\
0,0322 \\
0,0298 \\
0,0505 \\
0,0602 \\
0,0858 \\
0,0711 \\
0,0934 \\
\ldots\end{array}$ & $\begin{array}{r}0,0 \\
6,4 \\
13,6 \\
21,8 \\
32,1 \\
44,6 \\
51,1 \\
61,4 \\
75,9 \\
84,5 \\
93,2 \\
100,0\end{array}$ & $\begin{array}{l}180,5 \\
180,5 \\
180,5 \\
180,7 \\
180,3 \\
181,0 \\
181,0 \\
181,1 \\
181,7 \\
182,4 \\
182,0 \\
184,0\end{array}$ & $\begin{array}{l}182,0 \\
182,5 \\
182,5 \\
182,2 \\
182,4 \\
183,3 \\
183,6 \\
184,1 \\
184,4 \\
184,7 \\
185,7 \\
186,0\end{array}$ \\
\hline
\end{tabular}

Todas as misturas foram preparadas por meio de cuidadosa trituração das substâncias componentes.

Os pontos de degêlo e de fusão de cada mistura ioram sempre determinados nas mesmas amostras.

Os componentes formain uma série contínua de cristais mistos do tipo $l$. 
11. Sistema : Ácido naftalena-coleico( $1: 2)$ +ácido acenaftena-coleico $(1: 2)$

Fig. $\mathbf{V}, 3)$.

\begin{tabular}{|c|c|c|c|c|c|}
\hline $\mathrm{N} .{ }^{\circ}$ & $\begin{array}{l}\text { I. Ac. acenaftena- } \\
\text { coleico } \mathrm{g}\end{array}$ & $\begin{array}{l}\text { II. Ac.nuftalena- } \\
\text { coleico } \mathrm{g}\end{array}$ & $\%$ II & P.D. ${ }^{\circ} \mathrm{C}$. & P.F. ${ }^{\circ} \mathrm{C}$. \\
\hline $\begin{array}{r}1 \\
2 \\
3 \\
1 \\
5 \\
5 \\
6 \\
7 \\
8 \\
9 \\
10 \\
11 \\
12\end{array}$ & $\begin{array}{c}-\overline{0} \\
0,0882 \\
0,0733 \\
0,0455 \\
0,0546 \\
0,0377 \\
0,0263 \\
0,0197 \\
0,0120 \\
0,0119 \\
0,0050 \\
-\end{array}$ & $\begin{array}{c}-\overline{0} \\
0,0099 \\
0,0213 \\
0,0204 \\
0,0327 \\
0,0407 \\
0,0422 \\
0,0491 \\
0,0511 \\
0,0923 \\
0,0530 \\
-\end{array}$ & $\begin{array}{r}0,0 \\
10,1 \\
22,5 \\
31.0 \\
37, \tilde{5} \\
51,9 \\
61,6 \\
71,4 \\
81,0 \\
88,6 \\
91,4 \\
100,0\end{array}$ & $\begin{array}{l}174,5 \\
175,0 \\
175,5 \\
175,5 \\
175,5 \\
175,5 \\
175,7 \\
177,0 \\
177,5 \\
177,5 \\
177,6 \\
181,0\end{array}$ & $\begin{array}{l}176,5 \\
177,3 \\
177,8 \\
178,6 \\
178,6 \\
179,5 \\
179,8 \\
180,8 \\
181,7 \\
182,0 \\
182,0 \\
182,5\end{array}$ \\
\hline
\end{tabular}

Todas as raisturas foram preparadas por meio de intima trituração das substâncias componentes.

Os pontos de degêlo e de fusão de cada mistura foram sempre determinados nas mesmas amostras.

Os componentes formam uma série enntínua de cristais mistos do tipo I.

\section{Sistema: Ácido antracena-coleico(1:4)+ácido fenantrena-coleico(1:3)}

Fig. $V, 4)$.

Preparação do ácido fenantrena-coleico (1:3). ${ }^{37}$ ) A fenantrena (P.F. 96-98 $)$ foi recristalizada várias vezes de alcool absoluto até apresentar o P.F. $=99-100^{\circ}$.

$1,5 \mathrm{~g}$ de ácido desoxicólico e $0,2 \mathrm{~g}$ de fenantrena foram dissolvidos em $\mathrm{ca} .8 \mathrm{~cm}^{3}$ de alcool absoluto quente. O produto scparado por cristalização fundia a 182-183,50.

Todas as misturas foram preparadas por meio de intima trituração das substâncias componentes.

Todos os pontos de degêlo foram controlados num microscópio com chapa de aquecimento eletrica. - Os pontos de fusão foram determinados, como de costume, em tubos capilares de vidro. 
Os componentes formam uma série contínua de cristais mistos do tipo $I$.

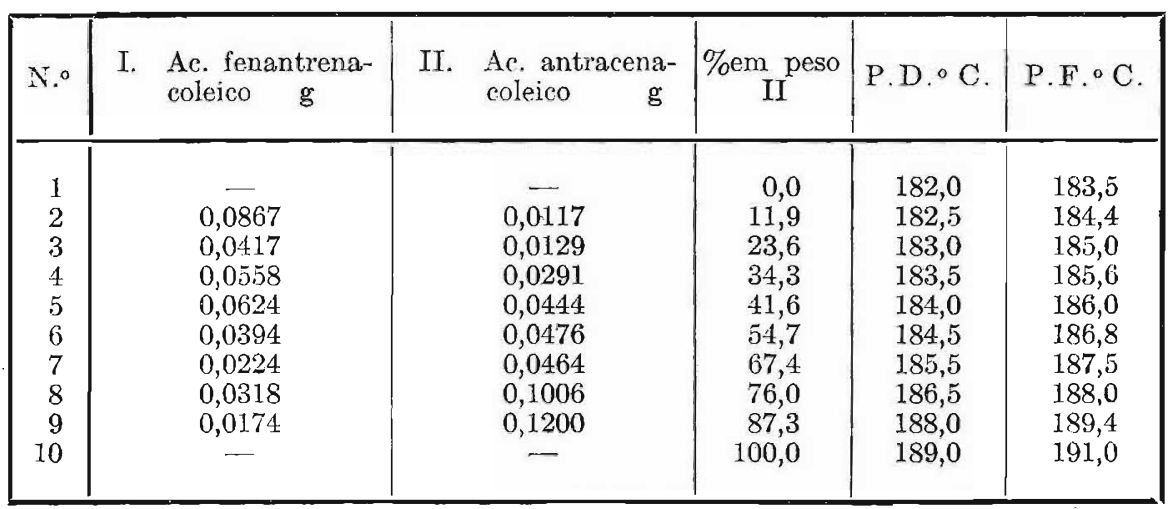

13. Sistema : Ácido antracena-coleico $(1: 4)$ +ácido acenaftena-coleico (1:2) Fig. V,5).

\begin{tabular}{|c|c|c|c|c|c|}
\hline$N .{ }^{\circ}$ & $\begin{array}{l}\text { I. Ac. acenaftena- } \\
\text { coleico } \mathrm{g}\end{array}$ & $\begin{array}{l}\text { IT. Ac. antracena- } \\
\text { coleico g }\end{array}$ & \%em peso & P.D. ${ }^{\circ} \mathrm{C}$. & P.F. C. \\
\hline $\begin{array}{r}1 \\
2 \\
3 \\
4 \\
5 \\
6 \\
7 \\
8 \\
9 \\
10\end{array}$ & $\begin{array}{c}-\overline{0} \\
0,0968 \\
0,0898 \\
0,0809 \\
0,0678 \\
0,0480 \\
0,0212 \\
0,0184 \\
0,0092 \\
-\end{array}$ & $\begin{array}{c}-\overline{-} \\
0,0051 \\
0,0150 \\
0,0236 \\
0,0388 \\
0,0488 \\
0,0390 \\
0,0787 \\
0,0880 \\
-\end{array}$ & $\begin{array}{r}0,0 \\
5,0 \\
14,3 \\
22,6 \\
36,4 \\
50,4 \\
64,8 \\
81,1 \\
90,5 \\
100,0\end{array}$ & $\begin{array}{l}173,5 \\
173,5 \\
173,5 \\
173,5 \\
173,8 \\
174,5 \\
176,0 \\
178,0 \\
181,5 \\
189,0\end{array}$ & $\begin{array}{l}175,5 \\
176,0 \\
176,2 \\
176,4 \\
177,2 \\
179,2 \\
182,0 \\
185,8 \\
187,8 \\
191,0\end{array}$ \\
\hline
\end{tabular}

Todas as misturas foram preparadas por meio de intima e cuidadosa trituração dos componentes.

Os pontos de degêlo e de fusão de cada mistura foram sempre determinados nas mesmas amostras.

Todas as misturas ao fundir adquirem uma coloraçăo amarela.

Os componentes formam uma série contínua de cristais mistos do tipo $I$. 
14. Sistema : Ácido fenantrena-coleico(1:3)+ácido acenaftena-coleico(1:2)

Fig. $\mathbf{V}, 6$ ).

Todas as misturas foram preparadas por meio de íntima trituração dos componentes.

Os pontos de degêlo e de fusão de cada mistura foram sempre determinados nas mesmas amostras.

Os componentes formam uma série contínua de cristais mistos do tipo I.

\begin{tabular}{|c|c|c|c|c|c|}
\hline N. ${ }^{\circ}$ & $\begin{array}{l}\text { I. Ac. acenaftena- } \\
\text { coleico } g\end{array}$ & $\begin{array}{l}\text { II. Ac. fenantrena- } \\
\text { coleico g } \mathrm{g}\end{array}$ & $\begin{array}{c}\text { \%em peso } \\
\text { II }\end{array}$ & P.D. ${ }^{\circ} \mathrm{C}$. & P. F. ${ }^{\circ}$ C \\
\hline $\begin{array}{r}1 \\
2 \\
3 \\
4 \\
5 \\
6 \\
7 \\
8 \\
9 \\
10 \\
11 \\
12\end{array}$ & $\begin{array}{c}\overline{-} \\
0,0738 \\
0,0511 \\
0,0549 \\
0,0440 \\
0.0388 \\
0,0301 \\
0,0272 \\
0,0235 \\
0,0124 \\
0,0071 \\
-\end{array}$ & $\begin{array}{c}\overline{0} \\
0,0056 \\
0,0118 \\
0,0165 \\
0,0180 \\
0,0260 \\
0,0300 \\
0,0416 \\
0,0562 \\
0,0522 \\
0,1063 \\
-\end{array}$ & $\begin{array}{r}0,0 \\
7,1 \\
18,8 \\
23,1 \\
29,0 \\
40,1 \\
49,9 \\
60,5 \\
70,5 \\
80,8 \\
93,7 \\
100,0\end{array}$ & $\begin{array}{l}173,5 \\
173,5 \\
173,5 \\
174,0 \\
174,0 \\
174,5 \\
175,0 \\
175,8 \\
176,2 \\
177,5 \\
180,5 \\
184,0\end{array}$ & $\begin{array}{l}175,5 \\
176,4 \\
177,2 \\
177,2 \\
177,5 \\
178,8 \\
179,4 \\
180,8 \\
182,4 \\
184,0 \\
185,6 \\
186,0\end{array}$ \\
\hline
\end{tabular}

15. Sisterna: Ácido naftalena-apocólico(1:2) +ácido esteárico-coleico (1:8)

Fig. VI,I).

Preparação do ácido naftalena-apọcélico $\left.(1: 2) \cdot{ }^{39}\right)$ 1,5g de ácido apocólico e 0,2g de naftalena foram dissolvidos em $8 \mathrm{~cm}^{3}$ de alcool metílico quente. Separou-se ao resfriar, um produto cristalino de P.F. $=171,2-174^{\circ}$. O composto, mesmo após várias recristalizações de alcool metílico, conservou inalterado o seu ponto de fusão.

As misturas foram todas preparadas por meio de íntima trituração dos componentes. - Algumas determinações executadas com misturas, obtidas por fusão das substâncias componentes, forneceram resultados muito discordantes.

Os pontos de degêlo e de fusão de cada mistura foranı determinados en amostras independentes.

Todas as misturas an fundir adquirem uma coloração amarela,

39) F. BOEDECKER. B. $58,1860(1920)$. - P.F. $=173-1740$. 


\begin{tabular}{|c|c|c|c|c|c|}
\hline N. ${ }^{\circ}$ & $\begin{array}{l}\text { I. Ac. naftalena- } \\
\text { apocólico g }\end{array}$ & $\begin{array}{l}\text { II. Ac. estéarico- } \\
\text { colei( } g \mathrm{~g}\end{array}$ & \%em peso & P.D." C. & P.F. C. \\
\hline $\begin{array}{r}1 \\
2 \\
3 \\
4 \\
5 \\
6 \\
7 \\
8 \\
9 \\
10 \\
11 \\
12 \\
13\end{array}$ & $\begin{array}{c}-\overline{0} \\
0,0950 \\
0,0955 \\
0,1057 \\
0,07 \pm 9 \\
0,0617 \\
0,0527 \\
0,0 \pm \pm 7 \\
0,0299 \\
0,022 \pm \\
0,0139 \\
0,0051 \\
--\end{array}$ & $\begin{array}{c}-\overline{0} \\
0,0075 \\
0,0138 \\
0,0260 \\
0,0278 \\
0,0356 \\
0,0518 \\
0,0657 \\
0,0704 \\
0,0859 \\
0,1095 \\
0,0962 \\
\ldots\end{array}$ & $\begin{array}{r}0,0 \\
7,3 \\
12,6 \\
19,7 \\
27,1 \\
36,6 \\
49,6 \\
59,5 \\
70,8 \\
79,3 \\
88,7 \\
92,2 \\
100,0\end{array}$ & $\begin{array}{l}171,2 \\
169,0 \\
169,0 \\
168,5 \\
168,0 \\
167,5 \\
166,2 \\
167,5 \\
170,0 \\
171,0 \\
173,8 \\
177,5 \\
186,0\end{array}$ & $\begin{array}{l}174,0 \\
174,0 \\
173,8 \\
173,5 \\
172,0 \\
172,5 \\
173,5 \\
176,2 \\
179,2 \\
181,0 \\
185,0 \\
185,4 \\
187,0\end{array}$ \\
\hline
\end{tabular}

Os componentes formam uma serie continua de cristais mistos.

16. Sistema : Ácido naftalena-aoocólico $(1: 2)+$ Ácido mirístiç-coleico $(1: 6)$ Fig. VI,2).

\begin{tabular}{|c|c|c|c|c|c|}
\hline $\mathrm{N}: 0$ & $\begin{array}{l}\text { I. Ac. naftalena- } \\
\text { aporólico g } g\end{array}$ & $\begin{array}{l}\text { II. Ac. mirítico- } \\
\text { coleien } \mathrm{g}\end{array}$ & $\begin{array}{c}\text { \%em peso } \\
\text { II }\end{array}$ & P.D. ${ }^{\circ}$. & P.F.C. \\
\hline $\begin{array}{r}1 \\
2 \\
3 \\
4 \\
5 \\
6 \\
7 \\
8 \\
9 \\
10 \\
11\end{array}$ & $\begin{array}{c}-\overline{0,0912} \\
0,0808 \\
0,0685 \\
0,0656 \\
0,0518 \\
0,0 \pm 11 \\
0,0319 \\
0,0208 \\
0,0106 \\
\end{array}$ & $\begin{array}{c}-\overline{0} \\
0,0096 \\
0,0209 \\
0,0300 \\
0,0412 \\
0,0523 \\
0,0683 \\
0,0752 \\
0,0820 \\
0,0951 \\
-\end{array}$ & $\begin{array}{r}0,0 \\
9,5 \\
20,6 \\
30,5 \\
38,6 \\
50,2 \\
62,4 \\
70,2 \\
79,8 \\
90,0 \\
100,0\end{array}$ & $\begin{array}{l}171,2 \\
164,0 \\
162,2 \\
161,0 \\
161,0 \\
161,0 \\
161,2 \\
162,0 \\
163,5 \\
167,0 \\
181,0\end{array}$ & $\begin{array}{l}174,0 \\
172,0 \\
169,0 \\
167,8 \\
167,4 \\
167,0 \\
169,0 \\
171,4 \\
174,0 \\
177,0 \\
182,0\end{array}$ \\
\hline
\end{tabular}

Todas as misturas foram preparadas por meio de cuidadosa tritur aģão das substâncias componentes. Algumas determinaçōes, executadas com misturas obtidas por meio de fusão dos componentes, forneceram resultados muito irregulares.

Todas as misturas ao ỉundir, adquirem uma coloração amarela.

Os componentes formam uma série contínua de cristais mistos. 
SEGUNDA PARTE

Sistemas binários de moléculas simples.

1. Sistema: Ácido desoxicólico + ácido apocólico.

Fig. VII.

\begin{tabular}{|c|c|c|c|c|c|}
\hline N. ${ }^{\circ}$ & $\begin{array}{l}\text { I. Ac. desoxi- } \\
\text { cólico } \mathrm{g}\end{array}$ & $\begin{array}{l}\text { II. Ac. apocó- } \\
\text { lico } \mathrm{g}\end{array}$ & \%em peso & P.D. ${ }^{\circ} \mathrm{C}$. & P.F. ${ }^{\circ}$ C. \\
\hline $\begin{array}{r}1 \\
2 \\
3 \\
4 \\
5 \\
6 \\
7 \\
8 \\
9 \\
10 \\
11 \\
12\end{array}$ & $\begin{array}{c}-\overline{0} \\
0,0908 \\
0,0790 \\
0,0698 \\
0,0747 \\
0,0588 \\
0,0522 \\
0,0387 \\
0,0306 \\
0,0212 \\
0,0094 \\
-\end{array}$ & $\begin{array}{c}\overline{0} \\
0,0094 \\
0,0205 \\
0,0321 \\
0,0440 \\
0,041.8 \\
0,0522 \\
0,0647 \\
0,0755 \\
0,0856 \\
0,0914 \\
-\end{array}$ & $\begin{array}{r}0,0 \\
9,4 \\
20,6 \\
31,4 \\
37,1 \\
41,6 \\
50,0 \\
62,6 \\
71,2 \\
80,2 \\
90,7 \\
100,0\end{array}$ & $\begin{array}{l}168,4 \\
162,0 \\
160,0 \\
158,5 \\
158,3 \\
158,5 \\
158,5 \\
159,0 \\
160,5 \\
161,5 \\
163,0 \\
168,2\end{array}$ & $\begin{array}{l}172,1 \\
171,0 \\
169,8 \\
169,5 \\
169,2 \\
169,0 \\
169,0 \\
169,5 \\
169,5 \\
170,5 \\
171,2 \\
173,2\end{array}$ \\
\hline
\end{tabular}

Ambos os ácidos foram secados no vácuo até peso constante, à temperatura de $100^{\circ} \mathrm{C}$.

Todas as misturas foram preparadas por meio de íntima e cuidadosa trituração das substâncias componentes.

Os pontos de degêlo e de fusão de cada mistura foram sempre determinados nas mesmas amostras.

Os componentes do sistema formam uma série contínua de cristais mistos.

\section{Sistema : Âcido esteárico + naftalena.}

O ácido esteárico e a naftalena foram purificados por recristalização de alcool absoluto. As misturas usadas nas determinações $n^{\circ}-6-9-13-$ foram preparadas por simples trituração dos componentes, as demais foram obtidas por meio de fusão parcial das substâncias componentes.

$O$ ponto de degêlo e o de fusão de cada mistura foram determinados em amostras independentes. 


\begin{tabular}{|c|c|c|c|c|c|}
\hline N.o & $\begin{array}{c}\text { I. Ac. esteárieo } \\
8\end{array}$ & II. Natalena & $\begin{array}{c}\% \text { em peso } \\
\text { II }\end{array}$ & P.D. ${ }^{\circ} \mathrm{C}$. & P.F. C. \\
\hline $\begin{array}{r}1 \\
2 \\
3 \\
4 \\
5 \\
6 \\
7 \\
8 \\
9 \\
10 \\
11 \\
12 \\
13 \\
14 \\
15 \\
16\end{array}$ & $\begin{array}{c}-\overline{1113} \\
0,0927 \\
0,0813 \\
0,0774 \\
0,0762 \\
00889 \\
0,0638 \\
0,0513 \\
0,0519 \\
0,0+13 \\
0,0285 \\
0,0232 \\
0,0102 \\
0,0055 \\
-\end{array}$ & $\begin{array}{c}- \\
0,0092 \\
0,0157 \\
0,0220 \\
0,0296 \\
0,0326 \\
00485 \\
0,0490 \\
0,0542 \\
0,0612 \\
0,0667 \\
0,0763 \\
0,0841 \\
0,0869 \\
0,0970 \\
\cdots\end{array}$ & $\begin{array}{r}0,0 \\
6,1 \\
14,5 \\
21,3 \\
27,7 \\
30,0 \\
35,3 \\
43,4 \\
50,0 \\
54,1 \\
61,8 \\
72,8 \\
78,4 \\
89,5 \\
94,6 \\
100,0\end{array}$ & $\begin{array}{l}68,8 \\
54,5 \\
55,0 \\
55,0 \\
54,5 \\
54,5 \\
55,5 \\
55,0 \\
54,5 \\
54,5 \\
55,0 \\
55,0 \\
55,0 \\
56,0 \\
56,5 \\
79,0\end{array}$ & $\begin{array}{l}80,0 \\
68,5 \\
65,5 \\
62,4 \\
60,5 \\
61, \tilde{5} \\
63,8 \\
68,0 \\
70,0 \\
71,5 \\
74,2 \\
76,0 \\
77,0 \\
78,5 \\
79,5 \\
80,0\end{array}$ \\
\hline
\end{tabular}

Os componentes do sistema formam um congionerado. O ponto eutético está situado, aproximadamente, nas cruamento das complenadas correspundentes a $24 \%$ em peso de naftalena a a $5.5 \%$.

3. Sirtema: Acido miristice + naftalena.

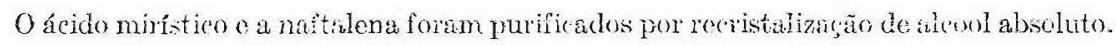

\begin{tabular}{|c|c|c|c|c|c|}
\hline N.o & $\begin{array}{l}\text { I. Ar. mirístico } \\
\mathrm{g}\end{array}$ & $\begin{array}{l}\text { II. Naftalena } \\
g\end{array}$ & \% em peso & P.D. ${ }^{\circ}$. & P. F. C. \\
\hline $\begin{array}{r}1 \\
2 \\
3 \\
4 \\
5 \\
6 \\
7 \\
8 \\
9 \\
10 \\
11 \\
12 \\
13\end{array}$ & $\begin{array}{c}\overline{0,1058} \\
0,0893 \\
0,0861 \\
0,0799 \\
0,0702 \\
0,0597 \\
0,0508 \\
0,0 \pm 16 \\
0,0315 \\
0,0201 \\
0,0110 \\
-.\end{array}$ & $\begin{array}{c}0,0065 \\
0,0114 \\
0,0168 \\
0,0203 \\
0,0301 \\
0,0400 \\
0,0546 \\
0,0634 \\
0,0710 \\
0,0885 \\
0,0 \$ 9 \\
-\cdots\end{array}$ & $\begin{array}{r}0,0 \\
5,8 \\
11,3 \\
16,3 \\
20,3 \\
30,0 \\
40,1 \\
51,8 \\
60,4 \\
69,3 \\
81,5 \\
89,0 \\
100,0\end{array}$ & $\begin{array}{l}52,5 \\
45,0 \\
44,0 \\
44,0 \\
44,0 \\
44,0 \\
44,0 \\
44,0 \\
44,0 \\
44,0 \\
44,0 \\
45,0 \\
79,0\end{array}$ & $\begin{array}{l}53,8 \\
52,8 \\
50,2 \\
48,2 \\
48,5 \\
55,4 \\
62,6 \\
70,5 \\
74,5 \\
75,6 \\
78,2 \\
79,4 \\
80,0\end{array}$ \\
\hline
\end{tabular}

As misturas usadas nas determinaçoses $n^{\circ}-2-3-4-12-$, foram preparadas por meio de fusão parcial dos componentes, as demais simplesnente por trituração. 
Os pontos de degêlo e de fusão de cadá mistura foram sempre determinados em amostras scparadas.

Os componentes do sitema formam um conglomerado. O ponto eutético está situado, aproximadamente, no cruzamento das coordenadas correspondentes a $18 \%$ em peso de naftalena c a $44^{\circ} \mathrm{C}$.

4. Sistema: Ảcido esteárico + antracena.

A antracena foi recristalizada várias vezes de uma mistura de alcool absoluto e benzena pura (1:1).

\begin{tabular}{|r|c|c|c|c|c|}
\hline $\mathrm{N} . \circ$ & I. Ac. esteárico & II. Antracena \\
$\mathrm{g}$ & & $\begin{array}{c}\text { \% em peso } \\
\text { II }\end{array}$ & P.D. o C. & P.F. . C. \\
\hline & & - & 0,0 & 68,8 & 70,0 \\
1 & - & 0,0045 & 4,5 & 67,0 & 131,5 \\
2 & 0,0953 & 0,0094 & 9,4 & 67,0 & 160,0 \\
3 & 0,0902 & 0,0208 & 20,4 & 67,0 & 173,0 \\
4 & 0,0813 & 0,0331 & 31,2 & 67,5 & 181,0 \\
5 & 0,0729 & 0,0382 & 42,5 & 67,5 & 190,5 \\
6 & 0,0516 & 0,0462 & 51,8 & 67,5 & 197,0 \\
7 & 0,0430 & 0,0501 & 61,5 & 68,0 & 202,0 \\
8 & 0,0313 & 0,0809 & 72,1 & 68,0 & 208,0 \\
9 & 0,0313 & 0,0876 & 83,9 & 70,0 & 212,0 \\
10 & 0,0168 & 0,1024 & 92,3 & 74,5 & 214,4 \\
11 & 0,0086 & - & 100,0 & 214,0 & 216,0 \\
12 & - & & & \\
\hline
\end{tabular}

As misturas com porcentagem baixa de um dos componentes, isto é, as correspon-

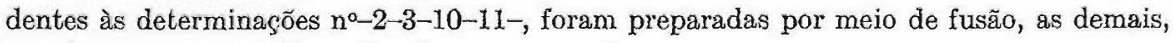
simplesmente por trituração dos componentes.

Os pontos de degêlo e de fusão de cada mistura foram sempre determinados em provas separadas.

Os componentes do sistema binário formam um conglomerado. O ponto eutético está situado, aproximadamente, no cruzamento das coordenadas correspondentes a $2 \%$ em peso de antracena e à temperatura de $67^{\circ} \mathrm{C}$. 
5. Sistema : Teido sstéáco + fenantroua.

A fenantrena fui purificada por meio de váriss recristolizacien de alcool absoluto.

\begin{tabular}{|c|c|c|c|c|c|}
\hline N.o & $\begin{array}{c}\text { I. Ac esteárico } \\
g\end{array}$ & II. Fenantrenis & $\begin{array}{c}\text { \%eru peso } \\
\text { II }\end{array}$ & P.D. ${ }^{\circ}$ C. & P.F. ${ }^{\circ}$. \\
\hline $\begin{array}{r}1 \\
2 \\
3 \\
4 \\
5 \\
6 \\
7 \\
8 \\
9 \\
10\end{array}$ & $\begin{array}{c}-\overline{0} \\
0,0956 \\
0,0746 \\
0,0780 \\
0,0613 \\
0,0250 \\
0,0139 \\
0,0148 \\
0,0080 \\
-\end{array}$ & $\begin{array}{c}\overline{0}, 0102 \\
0,0129 \\
0,0208 \\
0,0293 \\
0,0256 \\
0,0357 \\
0,0788 \\
0,0814 \\
-\end{array}$ & $\begin{array}{r}0,0 \\
9,6 \\
14,7 \\
21,1 \\
32,3 \\
50,0 \\
6,5,4 \\
84,2 \\
30,4 \\
100,0\end{array}$ & $\begin{array}{l}68,8 \\
61,5 \\
62,0 \\
62,0 \\
61,5 \\
62,5 \\
62,5 \\
63,5 \\
63,5 \\
99,0\end{array}$ & $\begin{array}{r}70,0 \\
68,0 \\
66,2 \\
63,8 \\
73,0 \\
86,0 \\
92,8 \\
98,0 \\
99,2 \\
100,0\end{array}$ \\
\hline
\end{tabular}

As misturas usadas nas determinacốcs $\mathrm{n}^{6-2}-3-8-9 \cdots$, form preparados por mein de fusão das substâncias componentes, as demais por simples mas perfeita trituragrão.

O: pontos de degêlo e de fusão de cadi mistura forsm sempre determinados $\mathrm{cm}$ cmostras independentes.

Os componentes formam um cinglonevado. O ponto eutético está situado, aproximadamente, no cruzamenta das coordenarlas correspoudentes a $23 \%$ em peso de forantrena e a $62^{\circ} \mathrm{C}$.

\section{Sistema: Ácido esteárics + accnaftena.}

A acenaftena foi recristalizada de alcool absoluto.

\begin{tabular}{|c|c|c|c|c|c|}
\hline N. ${ }^{\circ}$ & $\begin{array}{c}\text { I. Ac. esteárico } \\
\mathrm{g}\end{array}$ & $\begin{array}{c}\text { II. Acenaftena } \\
\mathrm{g}\end{array}$ & \%empeso & P.D. ${ }^{\circ} \mathrm{C}$ & P.F. ${ }^{\circ}$ C. \\
\hline $\begin{array}{r}1 \\
2 \\
3 \\
4 \\
5 \\
6 \\
7 \\
8 \\
9 \\
10 \\
11 \\
12 \\
13\end{array}$ & $\begin{array}{c}\overline{ } \\
0,0944 \\
0,1083 \\
0,0909 \\
0,0739 \\
0,0748 \\
0,0726 \\
0,0568 \\
0,0393 \\
0,0318 \\
0,0207 \\
0,0062 \\
-\end{array}$ & $\begin{array}{c}\overline{0} \\
0,0065 \\
0,011 \dot{4} \\
0,0140 \\
0,0153 \\
0,0252 \\
0,0391 \\
0,0578 \\
0,0612 \\
0,0769 \\
0,0831 \\
0,0616 \\
-\end{array}$ & $\begin{array}{r}0,0 \\
6,4 \\
9,5 \\
13,3 \\
17,2 \\
25,2 \\
35,0 \\
50,4 \\
60,9 \\
70,7 \\
80,1 \\
90,9 \\
100,0\end{array}$ & $\begin{array}{l}68,8 \\
61,5 \\
61,0 \\
61,0 \\
60,8 \\
60,5 \\
60,0 \\
60,5 \\
60,0 \\
60,5 \\
60,5 \\
61,5 \\
93,0\end{array}$ & $\begin{array}{l}70,0 \\
68,5 \\
67,5 \\
66,2 \\
65,0 \\
64,5 \\
75,0 \\
85,0 \\
88,0 \\
91,0 \\
92,2 \\
94,0 \\
95,0\end{array}$ \\
\hline
\end{tabular}


As misturas usadas nas determinações $n^{\circ}-2-4-5-$, foram preparadas por meio de fusão dos componentes, as restantes por simples mas íntima urituração.

Os pontos de degêlo e de fusão de todas as misturas foram sempre determinados em amostras independentes.

Os componentes do sistema formam um conglomerado. O ponto eutético está situado, aproximadamente, no cruzamento das coordenadas correspondentes a $22,5 \%$ em prese de acenaftena e a $60,5^{\circ}$

7. Sistema : Naftalena + acenaftena.

\begin{tabular}{|c|c|c|c|c|c|}
\hline $\mathrm{N} \cdot{ }^{\circ}$ & I. Naftalena & $\begin{array}{l}\text { II. Acenaftena } \\
g\end{array}$ & \%em peso & P.D. ${ }^{\circ} \mathrm{C}$. & P.F. C. \\
\hline $\begin{array}{r}1 \\
2 \\
3 \\
4 \\
5 \\
6 \\
7 \\
8 \\
9 \\
10 \\
11 \\
12 \\
13 \\
14 \\
15\end{array}$ & $\begin{array}{c}\overline{0} \\
0,0914 \\
0,0486 \\
0,0930 \\
0,0506 \\
0,0676 \\
0,0402 \\
0,0611 \\
0,0408 \\
0,0314 \\
0,0272 \\
0,0297 \\
0,0104 \\
0,0046\end{array}$ & $\begin{array}{c}- \\
0,0069 \\
0,0103 \\
0,0288 \\
0,0230 \\
0,0363 \\
0,0251 \\
0,0431 \\
0,0346 \\
0,0352 \\
0,0518 \\
0,0862 \\
0,0516 \\
0,0564\end{array}$ & $\begin{array}{r}0,0 \\
7,0 \\
17,5 \\
23,6 \\
31,9 \\
34,9 \\
38,4 \\
41,4 \\
45,9 \\
52,9 \\
65,6 \\
74,4 \\
83,2 \\
92,5 \\
100,0\end{array}$ & $\begin{array}{l}79,0 \\
53,0 \\
53,0 \\
52,5 \\
52,5 \\
52,5 \\
52,5 \\
52,5 \\
52,5 \\
52,5 \\
52,5 \\
52,5 \\
53,0 \\
53,5 \\
93,0\end{array}$ & $\begin{array}{l}80,0 \\
79,5 \\
77,0 \\
73,0 \\
70,0 \\
66,0 \\
63,5 \\
58,0 \\
58, \overline{3} \\
67,5 \\
76,5 \\
82,2 \\
87,0 \\
91, \overline{3} \\
9 \overline{5}, 0\end{array}$ \\
\hline
\end{tabular}

As misturas usadas nas determinações no-6-8-12-14-, foram preparadas por meio de fusão dos componentes, as restantes simplesmente por trituração.

Os pontos de degêlo e de fusão de todas as misturas foram sempre determinados em amostras independentes.

Os componentes formam um conglomerado. O ponto eutético está situado no cruzamento das coordenadas correspondentes a $43 \% \mathrm{em}$ peso de acenaftena e a $52^{\circ} \mathrm{C}$.

\section{Sistema : Acenaftena + antracena.}

As misturas usadas nas determinações $n^{\circ}-2-3-4-7-10-11-$, foram preparadas peln fusão parcial dos componentes, as demais, simplesmente por trituração. 
Os pontos de degĉlo e de fusão de cada mistura foram sempre determinados em amostras separadas.

\begin{tabular}{|c|c|c|c|c|c|}
\hline N. ${ }^{\circ}$ & $\begin{array}{l}\text { I. Acenaftená } \\
\mathrm{g}\end{array}$ & $\begin{array}{l}\text { II. Antracena } \\
\mathrm{g}\end{array}$ & $\begin{array}{c}\% \text { em peso } \\
\text { II }\end{array}$ & P.D. ${ }^{\circ}$ C. & P.F. ${ }^{\circ}$ C. \\
\hline $\begin{array}{r}1 \\
2 \\
3 \\
4 \\
5 \\
6 \\
7 \\
8 \\
9 \\
10 \\
11 \\
12\end{array}$ & $\begin{array}{c}-. \\
0,0997 \\
0,1176 \\
0,0820 \\
0,0483 \\
0,045.5 \\
0,0381 \\
0,0300 \\
0,0195 \\
0,0203 \\
0,0096 \\
-\end{array}$ & $\begin{array}{c}-\overline{0} \\
0,0025 \\
0,0086 \\
0,0200 \\
0,0225 \\
0,0320 \\
0,0385 \\
0,0458 \\
0,0444 \\
0,0859 \\
0,0884 \\
-\end{array}$ & $\begin{array}{r}0,0 \\
2,5 \\
6,8 \\
19,6 \\
31,8 \\
41,3 \\
50,3 \\
60,4 \\
69,5 \\
80,9 \\
90,2 \\
100,0\end{array}$ & $\begin{array}{r}94,0 \\
89,0 \\
88,5 \\
88,5 \\
89,0 \\
89,0 \\
89,2 \\
89,0 \\
89,2 \\
90,0 \\
92,2 \\
213,5\end{array}$ & $\begin{array}{r}95,0 \\
93,4 \\
112,0 \\
128,0 \\
145,0 \\
158,4 \\
169,4 \\
179,0 \\
188,2 \\
199,0 \\
107,5 \\
215,0\end{array}$ \\
\hline
\end{tabular}

Os componentes formam um conglomerado. O ponto eutético está situado, aproximadamente, no cruzamento das coordenadas correspondentes a $1,5 \% \mathrm{~cm}$ peso de antracena e a $89^{\circ} \mathrm{C}$.

9. Sistema : Acenaftena + fenantrena.

\begin{tabular}{|c|c|c|c|c|c|}
\hline N. ${ }^{\circ}$ & $\begin{array}{c}\text { I. Acenaftena } \\
\mathrm{g}\end{array}$ & II. Fenantrena & $\begin{array}{c}\% \text { em peso } \\
\text { II }\end{array}$ & P.D. ${ }^{\circ}$. & P.F. C. \\
\hline $\begin{array}{r}1 \\
2 \\
3 \\
4 \\
5 \\
6 \\
7 \\
8 \\
9 \\
10\end{array}$ & $\begin{array}{c}-\overline{-} \\
0,0942 \\
0,0626 \\
0,0507 \\
0,0486 \\
0,0582 \\
0,0291 \\
0,0208 \\
0,0120 \\
-\end{array}$ & $\begin{array}{c}\overline{0,0058} \\
0,0113 \\
0,0206 \\
0,0340 \\
0,0562 \\
0,0444 \\
0,0617 \\
0,0864 \\
-\end{array}$ & $\begin{array}{r}0,0 \\
5,8 \\
15,3 \\
28,9 \\
41,2 \\
49,1 \\
60,4 \\
74,8 \\
87,8 \\
100,0\end{array}$ & $\begin{array}{l}94,0 \\
59,5 \\
59,0 \\
59,2 \\
59,0 \\
59,0 \\
59,2 \\
59,5 \\
60,0 \\
98,0\end{array}$ & $\begin{array}{r}95,0 \\
\$ 2,5 \\
89,0 \\
82,5 \\
74,0 \\
64,4 \\
65,2 \\
80,5 \\
93,0 \\
100,0\end{array}$ \\
\hline
\end{tabular}

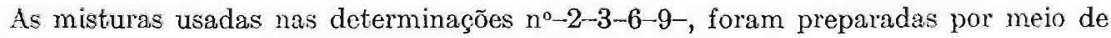
fusão dos componentes, as restantes por simples mas íntima trituração.

Os pontos de degêlo e de fusão de todas as misturas foram sempre determinados em amostras separadas.

Os componentes do sistema formam um conglomerado. O ponto eutético está situado no cruzamento das coordenadas correspondentes a $51,5 \%$ em peso de fenantrena e a $59^{\circ} \mathrm{C}$. 


\section{ZUSAMMENFASSUNG}

Durch Bestimmung der Zustandsdiagramme binärcr Systeme mittels der AuftauSchmelzmethode von H. RhernboldT wird festgestellt, dass die verschiedensten Choleinsäuren befähigt sind, mit einander lückenlose Mischkrystallreihen zu bilden. Hieraus ist der Scbluss zu ziehen, dass diese Moleküiverbindungen trotz der Verschiedenheit der Komponenten und ihres Zusammensetzungsverhaeltnisses einen analogen Krystallbau besitzen.

1) Es bilden lückenlose Mischkrystallireihen des Typus I die binären Systeme :

Stearincholeinsaeure und Palmitincholeinsaeure

Stearincholeinsaeure und Myristincholeinsaeure

Stearincholeinsaeure und Laurincholeinsaeure

Arachincholeinsaeure und Taurincholeinsauere

Vergi. Fig. III.

Ferner :

Naphtalincholeinsaeure und Anthracencholeinsaeure

Taphtalincholeinsaeure und Phenanthrencholeinsaeure

Naphtalincholeinsaeure und Acenaphtencholeinsaeure

Anthracencholcinsaeure und Phenanthrencholeinsaeure

Anthracencholeinsaeure und Acenaphtencholeinsaeure

Phenanthrencholeinsaeure und Acenaphtencholeinsaeure

Vergi, Fig. V.

2) Mischkrystallreihen des Typus III bilden die binären Systeme folgender Choleinsäuren :

Stearincholeinsaeure und Xaphtalincholeinsaeure

Stearincholeinsaeure und Anthracencholeinsaeure

Stearincholeinsaeure und Phenanthrencholeinsaeure

Stearincholeinsaeure und Acenaphtencholeinsaeure

Vergl. Fig. IV.

3) In den binären Systemen :

Naphtalin-apocholsaeure und Stearincholeinsaeure

Naphtalin-apocholsaeure und Myristincholeinsaeure

treten Mischkrystallreihen desselben Typs wie bei 2) auf.

Vergl. Fig. VI.

4) Desoxycholsaeure und Apocholsaeure bilden eine unterbrochene Reihe von Mischkrystallen. 
Vergl. Fig: VIr.

5) Einfache Eutektika, ohne Anzeichen von Mischkrystallbildung, treter auf in den binären Systemen folgender Stoffe, die als Komponenten vorerwähnter Choleitrsaeuren fungieren.

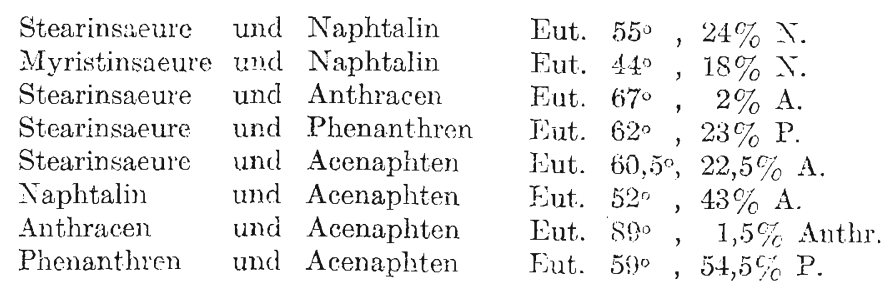

\section{SUMMARY}

The determination of the diagrams of state of binary systems, carried out by $\mathrm{H}$. RaeinsoldT's method (Auitau-Schmelzmethode"), shows that the most different choleic acids are able to form unbroken series of mixed crystals with each other. From this fact arises the conclusion that these molecular compounds, in spite of the unlike nature of their components and the difference in their proportions of composition, have an analogous crystalline structure.

1) The follorving binary systems form unbroken series of mixed crystals of type $I$ :

Stearic-choleic acid and palmitic-choleic acid

Stearic-choleic acid and myristic-choleic acid

Stearic-choleic acid and lauric-choleic acid

Arachic-choleic acid and lauric-choleic acid

Comp. Fig. III

In the same way behave:

Naphtalene-choleic acid and anthracene-choleic acid

Naphtalene-choleic acid and phenanthrene-choleic acid

Naphtalene-choleic acid and acenaphtene-choleic acid

Anthracene-choleic acid and phenanthrene-choleic acid

Anthracene-choleic acid and acenaphtene-choleic acid

Phenanthrene-choleic acid and acenaphtene-choleic acid

Comp. Fig. V

2) Binary systems of the following choleic acids give rise to continuos series of mixed crystals of type III :

Stearic-choleic acid and naphtalene-choleic acid Stearic-choleic acid and antrhacene-choleic acid Stearic-choleic acid and phenanthrene-choleic acid Stearic-choleic acid and acenaphtene-choleic acid 


\section{Comp. Fig. IV}

3) In the binary systems:

Naphtalene-apocholic acid and stearic-choleic acid

Naphtalene-apocholic acid and myristic-choleic acid

are formed mixed crystals of the same type as appearing in case 2).

\section{Comp. Fig. VII}

4) Desoxycholic acid and apocholic acid form an unbroken series of mixed crystals.

\section{Comp. Fig. VII}

5) In the diagrams of the systems of the following substances, acholic components of the choleic acid mentioned above, only one eutectic point is found, without any indication of mixed crystals.

Stearic acid and Naphtalene Myristic acid and Naphtalene Stearic acid and Anthracene Stearic acid and Phenanthrene Stearic acid and Acenaphtene Naphtalene and Acenaphtene Anthracene and Acenaphtene Phenanthrene and Acenaphtene
Eut. $55^{\circ}, 24 \% \mathrm{~N}$.

Eut. $44^{\circ}, 18 \% \mathrm{~N}$.

Eut. $67^{\circ}, 2 \% \mathrm{~A}$.

Eut. $62^{\circ}, 23 \%$ P.

Eut. $60,55^{\circ}, 22,5 \%$ A.

Eut. $52^{\circ}, 43 \%$ A.

Eut. $89^{\circ}, 1,5 \%$ Anthr

Eut. $59^{\circ}, 54,5 \%$ P. 